\title{
RELATÓRIO DA REUNIÃO TÉCNICA DE ORDENAMENTO DA PESCA DE ARRASTO NAS REGIÕES SUDESTE E SUL DO BRASIL
}

\section{APRESENTAÇÃO}

As pescarias industriais de arrasto, de camarões e de peixes, na plataforma continental das regiões Sudeste e Sul do Brasil, vêm sendo regulamentadas pelos organismos federais gestores da atividade pesqueira (SUDEPE e, posteriormente, IBAMA), desde a década de 1970.

A necessidade da adoção de medidas normativas para esses segmentos produtivos manifestou-se, enfaticamente, a partir da expressiva queda no rendimento da captura de camarão-rosa, em 1973, que persiste desde então. Tal situação foi determinada por instantâneos e exagerados crescimentos da frota, por conta, inicialmente, da política de incentivos fiscais à pesca (início dos anos 70) e, mais tarde (meados da década de 80), pelas facilidades de investimento proporcionadas por um plano econômico (Cruzado) do Governo Federal. Como conseqüência, muitas unidades camaroneiras passaram a atuar em parelhas, no arrasto de peixes, e outras tantas a operar em ambas as modalidades.

As medidas de regulamentação do arrasto até aqui adotadas abrangem a limitação do esforço de pesca, via licenciamento e limitação das frotas; caracterização de petrechos/ equipamentos de pesca e restrição de uso; proteção de áreas de pesca; tamanho mínimo de captura das espécies-alvo; e, para camarões, períodos de defeso (proibição de pesca).
Embora tecnicamente adequadas para garantir a sustentabilidade das pescarias, essas normas têm sido freqüente e intensamente burladas, demonstrando pouca eficácia. Para isso, concorrem a postura inconseqüente de grande parte do segmento produtivo, que ainda não assimilou o fato de que os recursos naturais renováveis não são inesgotáveis; a falta de uma atitude politicamente mais responsável dos agentes gestores da pesca; e a notória deficiência do setor de fiscalização da mesma.

Duas reuniões técnicas promovidas pelo IBAMA, em 2000, para avaliação do estado da arte e ordenamento das pescarias de camarões e de peixes demersais no Sudeste e Sul, patentearam o estado de crise que envolve ambas as atividades e, mais, a desordem que a rege.

Diante disso, reunião específica foi realizada, em 2001, buscando encontrar um novo modelo para o ordenamento das mesmas, cujos resultados são apresentados no presente relatório.

Tratando-se de uma proposta inédita e, eventualmente, polêmica, o corpo técnico que a elaborou houve por bem dar-lhe ampla divulgação, razão por que o trabalho está sendo editado neste Volume Especial da Revista Notas Técnicas da FACIMAR.

Os Editores 
PEREZ et al.: Ordenamento da Pesca de Arrasto no Sudeste-Sul do Brasil. 


\title{
RELATÓRIO DA REUNIÃO TÉCNICA DE ORDENAMENTO DA PESCA DE ARRASTO NAS REGIÕES SUDESTE E SUL DO BRASIL
}

\author{
07 a 11 de maio de 2001 \\ CEPSUL/IBAMA \\ Itajaí - SC
}

\begin{abstract}
PEREZ, J. A. A. ${ }^{\text {; }}$ PEZZUTO, P. R. ${ }^{1}$; RODRIGUES, L. F. ${ }^{2}$; VALENTINI, H. ${ }^{3}$ \& C.M. VOOREN ${ }^{4}$
\end{abstract}
(Relatores)

${ }^{1}$ CTTMar/UNIVALI (SC); ${ }^{2}$ CEPSUL/IBAMA (SC); ${ }^{3}$ Instituto de Pesca (SP); ${ }^{4}$ FURG (RS)

\section{INTRODUÇÃO}

A Política Pública do Gerenciamento Costeiro foi introduzida no País na década de 1980, por meio de um planejamento de gestão integrada, descentralizada e participativa dos recursos naturais e dos ecossistemas costeiros (PNGC - Lei 7.661 de 16/05/1988).

Um dos princípios norteadores do gerenciamento costeiro é representado pelo processo de gestão compartilhada dos recursos, o que permite a diferentes segmentos da sociedade, desde as comunidades de pescadores artesanais que operam na área até os empresários e armadores da pesca industrial, em co-responsabilidade com o Estado, dentre outros setores, operarem uma parceria responsável, onde a atividade produtiva e o respeito aos balizamentos da natureza devam ser observados. Este fato legitima as medidas que estabelecem critérios para o uso sustentado dos recursos ambientais, obrigando as partes envolvidas a assumirem, compartilhadamente, os direitos, as responsabilidades, os proble- mas e os esforços advindos de sua implementação.

No ano anterior, foram realizadas no CEPSUL/IBAMA duas reuniões para avaliar e discutir, distintamente, o Estado da Arte e Ordenamento da Pesca de Camarões (Novembro/2000) e da Pesca de Arrasto de Peixes Demersais (Dezembro/2000) nas Regiões Sudeste e Sul do Brasil. A dinâmica de trabalho empregada em ambas foi idêntica, com a participação do setor produtivo (armadores e pescadores), representado por sindicatos e associações de classe, técnicos e pesquisadores de diversas instituições que estão desenvolvendo trabalhos de pesquisa em áreas correlatas aos temas em pauta, e dos setores de fiscalização do IBAMA e das polícias militares dos estados. Após as sessões de palestras e apresentação de trabalhos, os participantes foram divididos em grupos afins, para discussões e formulação de propostas de ordenamento.

Estas propostas, levadas às sessões plenárias, foram amplamente debatidas, originando as recomendações constantes nos res- 
pectivos relatórios e, no caso específico da pescaria de camarão, foi aprovada uma proposta de portaria para o defeso do corrente ano.

Um fato marcante durante as discussões da Reunião de Camarões e que motivou novos debates na Reunião de Peixes Demersais, foi o reconhecimento unânime, pelos participantes, da inexistência de frotas especificas para a captura desses recursos, apesar do licenciamento, quando existente, assim o determinar. Já não subexiste uma frota arrasteira especificamente atuante sobre os recursos camarões e outra sobre os recursos peixes demersais. As informações técnicas apresentadas e o depoimento pessoal dos armadores presentes indicam que ambas as frotas estão atuando sobre os estoques que estiverem mais disponíveis em determinado momento.

A depleção dos estoques de camarões levou a frota camaroneira a buscar a sustentabilidade econômica de sua atividade na captura de peixes, tradicionalmente pescados pela frota de arrasto de peixe. Esta, por sua vez, tenta manter seu nível de rentabilidade capturando outras espécies que, por força de mercado, passaram a ser economicamente atrativas. Em suma, as frotas tornaram-se naturalmente multiespecíficas, quase sem fronteiras impeditivas para qualquer recurso, agravando, assim, o comprometimento de estoques sobreexplotados ou mesmo em vias de exaustão.

Esta evidência foi o fator determinante para que o IBAMA assumisse o compromisso de iniciar ampla discussão em busca de um novo modelo de administração, mais abrangente, de forma a proteger ambas categorias de recursos. Partindo-se desta premissa e considerando a magnitude das espécies envolvidas, bem como as dimensões geográficas do ambiente marinho onde a pesca é exercida, o manejo da atividade deve necessariamente começar pela elaboração e implementação de novo modelo de ordenamento para a pesca de arrasto como um todo. Em síntese, deve-se substituir a admi- nistração pesqueira por tipo de recurso pelo gerenciamento da modalidade de pesca, no caso, o arrasto.

Visando a implementação deste novo modelo, o CEPSUL/IBAMA promoveu, em primeira instância, no período de 7 a 11 de maio de 2001, reunião de caráter eminentemente técnico para avaliar, à luz das informações disponíveis, a viabilidade desta proposta arrojada. As informações disponibilizadas neste relatório constituem o alicerce para o inicio de ampla discussão e refletem a tendência que amplia o conceito de sustentabilidade, para além da ótica meramente ecológica, trazendo à discussão o setor produtivo e a visão institucional, e reforçando o processo de gestão participativa.

\section{OBJETIVO}

A finalidade desta reunião foi a elaboração de uma nova proposta de ordenamento para a pesca de arrasto, a partir dos seguintes temas:

a) Dimensionamento da frota de arrasteiros em operação nas regiões Sudeste e Sul, por categoria (parelha, arrasteiros simples e duplo e arrasteiro de pequeno porte).

b) Avaliação dos níveis recentes de captura, por espécie, e estimativa do rejeito produzido pelas diversas frotas.

c) Avaliação da distribuição espacial e temporal das operações de pesca de arrasto.

d) Revisão das medidas de manejo vigentes na pesca de arrasto das regiões Sudeste e Sul, por estado e ecossistema.

\section{PARTICIPANTES}

Participaram da reunião vinte técnicos e pesquisadores vinculados a diversas instituições de pesquisa do Sudeste-Sul do Brasil e 
cuja área de atuação abrange a investigação dos recursos demersais nas suas mais variadas frentes, além de suas entidades manterem coleta regular de informações pesqueiras nos estados da região (FURG, UNIVALI, CEM/ UFPR, Instituto de Pesca e Unidades do IBAMA):

Acácio Ribeiro Gomes Tomás - I.PESCA-SP Antônio Alberto da Silveira Menezes - IBAMARJ

Arcimi dos Santos - Consultor-ES

Carlos Alberto Borzone - UFPR-PR

Carolus Maria Vooren - FURG-RS

David de Carvalho Figueiredo - IBAMA-SC

Fernando D'Incao - FURG-RS

Hélio Valentini - I.PESCA-SP

José Angel Alvarez Perez - UNIVALI-SC

Lício George Domit - IBAMA-PR

Luiz Arnaud Britto de Castro - I.PESCA-SP

Luiz Fernando Rodrigues - CEPSUL/IBAMASC

Manuel Haimovici - FURG-RS

Marcelo Vianna - I.PESCA-SP

Paulo Ricardo Pezzuto - UNIVALI-SC

Ricardo Castelli Vieira - CEPSUL/IBAMA-SC

Sebastião Saldanha - DEPAQ/IBAMA-DF

Suzana Anita Saccardo - IBAMA-SP

Thais Mehl Ribas - UNIVALI-SC

Vera Silva - CEPERG/IBAMA-RS

\section{METODOLOGIA DE TRABALHO}

Aos participantes foram requisitadas, previamente, as seguintes informações:

* Número de barcos em atividade (independente da categoria, industrial e artesanal), com informações complementares das características físicas (ano de fabricação; TAB; TL; comprimento total; HP) e tipo de licença de pesca;

* Desembarque das principais espécies capturadas pela frota de arrasto e informações qualiquantitativas disponíveis sobre a fauna acompanhante (incluindo rejeito) nas pescarias;
* Indicação das principais áreas e épocas de pesca das referidas espécies, por tipo de pescaria;

* Levantamento da legislação pesqueira existente para o ordenamento da pesca de arrasto, por estado e ecossistema.

\section{a) Dimensão da frota de arrasteiros}

O dimensionamento da frota de arrasteiros atuantes no Sudeste-Sul foi efetuado por meio da consolidação das listagens produzidas pelas instituições participantes, referentes às embarcações cujos desembarques foram registrados, ao menos uma vez, durante o ano de 2000, nos portos do RS, SC e SP, e em 1999 no RJ e ES. Após a reunião de todos os dados existentes, os mesmos foram confrontados, sendo então elaborada uma listagem única, contendo o universo de embarcações atuantes na região. Foi igualmente analisada a "fidelidade" das embarcações aos respectivos portos, verificando-se o número de ocorrências de desembarques de cada unidade nos diferentes estados da região, com o objetivo de se avaliar o grau de sobreposição das respectivas frotas.

b) Estimativa do desembarque total das frotas e do rejeito

Elaborou-se uma matriz de desembarque para as frotas de arrasto de toda a região sudeste-sul, reunindo-se os dados disponíveis em cada estado para os anos de 1998 e 1999. Além disso, foram igualmente disponibilizados e analisados dados preliminares dos desembarques referentes ao ano 2000 nos estados de SC e RS. Com o objetivo de se avaliar qual o nível de sobreposição das capturas das frotas de arrasto e emalhe, elaborou-se uma matriz similar de desembarques para esta última frota, a partir de dados coletados no RJ em 1999, em SP e SC em 1998 e 1999 e no RS nos anos de 1999 e 2000. 
Os desembarques foram agrupados por estado, espécie e frota. A frota de arrasteiros da região foi classificada por conveniência em (a) arrasteiros simples (embarcações que arrastam com portas e uma única rede), (b) arrasteiros duplos (embarcações que arrastam com duas redes e utilizam tangones e portas), (c) arrasteiros de parelha (embarcações que arrastam, em duplas, uma única rede) e (d) arrasteiros de pequeno porte (considerados como as embarcações menores de 15 metros, que arrastam com uma ou duas redes em áreas costeiras).

Os nomes vulgares das espécies foram revisados, visando uniformizar a nomenclatura entre os diversos estados e produzir uma listagem única dos desembarques de toda a região.

Após a consolidação das informações, os dados de desembarques foram analisados, verificando-se os principais componentes da captura em cada estado e frota, tanto por espécies como por grandes grupos, assim definidos: teleósteos, elasmobrânquios, crustáceos, cefalópodes e mistura.

Por fim, foi efetuada uma estimativa da quantidade de rejeito produzida pela pesca de arrasto da região, tomando-se por base as informações dos desembarques e as proporções de rejeição disponíveis na bibliografia.

Para cada petrecho e para cada estado, produziu-se uma estimativa de desembarque total $(\mathrm{Dt})$, rejeito total $(\mathrm{Rt})$ e captura total $(\mathrm{Ct})$ em todo o período, tal que:

$$
r c=\frac{R_{t}}{C_{t}} \times 100 \Rightarrow r c=\frac{R_{t}}{\left(R_{t}+D_{t}\right)} \times 100
$$

onde rc é a proporção rejeitada do total capturado.

A estimativa do rejeito total $(\mathrm{Rt})$ foi realizada por estado e petrecho, de acordo com critérios específicos, levando-se em conta o alvo da pescaria (arrasto de peixe e arrasto de ca- marão); Rt seria a soma do rejeito total estimado, por estado, na pesca de arrasto de peixe $(R p)$ e na pesca de arrasto de camarão $(R c)$.

Para a estimativa de Rp e Rc foram considerados, em cada petrecho, além do desembarque total (Dt), o de camarões (Dc), o de peixes (Dt) e de mistura (Dm); e os coeficientes rdp (rejeito como proporção do desembarque total da pesca de arrasto de peixes) e rdc (rejeito como proporção do desembarque total da pesca de arrasto de camarões), sendo, em geral,

$$
R_{t}=\left(D_{p} \times r d p\right)+\left(D_{c} \times r d c\right)
$$

Estes coeficientes, rdp e rdc, foram adotados a partir da bibliografia disponível para cada petrecho e estado da região sudeste-sul, estando relacionados na Tabela 1. Utilizaramse, ainda, os termos rdcs para especificar o rejeito na pesca dos camarões do Rio Grande do Sul e rdcr para o rejeito na pesca do camarão-rosa.

A seguir, são apresentados procedimentos específicos adotados em cada petrecho e estado.

\section{* Pesca de Parelha e Arrasto Simples (RS)}

O arrasto de parelha é direcionado exclusivamente a peixes, em todos os estados do Sudeste e Sul. Assim, o cálculo do Rt correspondeu à equação 2, porém, apenas com o primeiro termo, referente ao rejeito na pesca de peixes. Adotaram-se, em todos os estados (RS, SC e SP), valores de rdp $=0,5$, indicando que cerca de $50 \%$ da captura total desembarcada tenha sido rejeitada (Tabela 1).

\section{*Pesca de Arrasto Duplo}

O arrasto duplo de plataforma pode ser direcionado à pesca de camarões e à pesca de peixes, sendo que, ainda, foram considerados distintos os padrões de rejeito da pesca 
Tabela 1. Coeficientes utilizados para a estimativa do rejeito total nas capturas da pesca de arrasto, por petrecho e estado das regiões Sudeste e Sul.

\begin{tabular}{|c|c|c|c|c|c|}
\hline \multicolumn{2}{|c|}{ Petrecho/Estado } & \multirow{2}{*}{$\begin{array}{c}\text { Camarões } \\
\text { Sul } \\
r d c s\end{array}$} & \multirow{2}{*}{$\begin{array}{c}\text { Camarão- } \\
\text { rosa } \\
r d c r\end{array}$} & \multirow{2}{*}{$\begin{array}{c}\text { Camarão } \\
\text { sete-barbas } \\
\text { cip } \\
\end{array}$} & \multirow{2}{*}{ 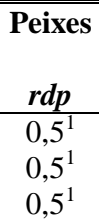 } \\
\hline Arrasto de Parelha & $\begin{array}{l}\text { RS } \\
\text { SC } \\
\text { SP }\end{array}$ & & & & \\
\hline Arrasto Simples & $\mathbf{R S}$ & & & & $0,5^{1}$ \\
\hline Arrasto Duplo & $\begin{array}{l}\text { RS } \\
\text { SC } \\
\text { SP } \\
\text { RJ } \\
\end{array}$ & $\begin{array}{l}0,5^{2} \\
0,5^{3}\end{array}$ & $\begin{array}{l}7,0^{3} \\
9,0^{4} \\
9,0^{5}\end{array}$ & & $\begin{array}{l}0,5^{2} \\
0,5^{3} \\
0,5^{4} \\
0,5^{5}\end{array}$ \\
\hline $\begin{array}{c}\text { Arrasto Pequeno } \\
\text { porte }\end{array}$ & $\begin{array}{l}\text { SC } \\
\text { PR } \\
\text { SP } \\
\text { RJ } \\
\text { ES }\end{array}$ & & & $\begin{array}{l}1,0^{6} \\
1,0^{6} \\
1,0^{6} \\
1,0^{6} \\
1,0^{6}\end{array}$ & \\
\hline
\end{tabular}

${ }^{1}$ Haimovici \& Palacios-Maceira, 1981; Kotas, 1991;

${ }^{2}$ Haimovici \& Mendonça, 1996a;

${ }^{3}$ Haimovici \& Mendonça, 1996a; Kotas, 1998

${ }^{4}$ Alverson et al., 1994

${ }^{5}$ Haimovici \& Mendonça,1996a; Kotas, 1998

${ }^{6}$ Paiva-Filho \& Schimiegelow, 1986; Graça-Lopes, 1996

direcionada ao camarão-rosa (Farfantepenaeus paulensis e F. brasiliensis) e aos camarões do Rio Grande do Sul (camarão-barba-ruça, Artemesia longinaris, e camarão-santana, Pleoticus muelleri).

\section{$\underline{\text { Rio Grande do Sul }}$}

Os totais desembarcados expressam as capturas de arrasteiros direcionados a peixes e camarões, sem discriminação. Assim, o desembarque de peixes (Dp) foi estimado a partir da subtração do desembarque de camarões (Dc) do desembarque total (Dt) e, portanto, a equação 2 foi transformada em:

$$
R_{t}=\left[\left(D_{t}-D_{c}\right) \times r d p\right]+\left(D_{c} \times r d c s\right)
$$

Para ambas pescarias o rejeito correspondeu a $50 \%$ do total desembarcado, quer de camarões quer de peixes $(\mathrm{rdcs}$ e $\mathrm{rdp}=$ 0,5) (Tabela 1).

\section{Santa Catarina}

Assim como no Rio Grande do Sul, os desembarques totais não discriminam 0 direcionamento a peixes ou camarões. Por outro lado, também aparece o elemento mistura como desembarque de peixes não categorizados $(\mathrm{Dm})$. Além disso, parte da frota direcionada à pesca de camarões atua sobre os camarões do sul e parte sobre o camarãorosa, numa proporção de $80 \%$ e $20 \%$, respectivamente. Assim, os desembarques totais de camarões foram inicialmente discriminados em desembarques de camarões do sul e desembarques de camarão-rosa. Da mesma forma que para o Rio Grande do Sul, os desembarques de peixes (Dp) foram estimados, subtraindo-se os desembarques de camarões dos 
desembarques totais (Dt). A equação 2 foi, então, transformada em:

$\left.R_{t}=\left[\left(D_{t}-D_{c}-D_{m}\right) \times r d p\right]+\left\{\left(D_{c} \times 0,8 \times r d c s\right)+\left(D_{c} \times 0,2 \times r d c r\right)\right]-D_{m}\right\}$

onde rdcs e rdcr correspondem ao rejeito como proporções do desembarque de camarões do sul e camarão-rosa respectivamente (Tabela 1). Nas estimativas de rejeito na pesca direcionada a camarões e peixes foram subtraídos os totais desembarcados na categoria mistura (Dm).

\section{$\underline{\text { São Paulo }}$}

A pesca de arrasto em São Paulo é direcionada ao camarão-rosa e a peixes. Assim, aplicou-se a equação 2 transformada, tal como no Rio Grande do Sul, adotando-se os coeficientes 0,5 e 0,9 para rdp e rdcr. A mistura foi descontada em ambas estimativas de rejeito, tal qual em Santa Catarina.

$R_{t}=\left[\left(D_{t}-D_{c}-D_{m}\right) \times r d p\right]+\left[\left(D_{c} \times r d c r\right)-D_{m}\right]$

\section{Rio de Janeiro}

O pesca de arrasto duplo no Rio de Janeiro recebeu o mesmo tratamento da pesca em São Paulo, variando-se apenas os coeficientes rdp e rdcr, considerados 0,5 e 9,0, uma vez que se estima que, para cada quilo de camarão estocado, são rejeitados 9 quilos de peixe (Tabela 1). Assim, o cálculo do rejeito total (Rt) foi realizado com a mesma modificação da equação 2 apresentada para o Estado de São Paulo.

\section{${ }^{*}$ Arrasto de pequeno porte}

O arrasto de pequeno porte está direcionado à pesca do camarão sete-barbas em todos os estados das regiões Sudeste e Sul, à exceção do Rio Grande do Sul. Neste caso, estima-se que, para cada quilo captura- do de camarão, captura-se um quilo de peixe e, assim, o desembarque total de camarão (Dc) equivale à captura incidental total de peixes; no entanto, apenas parte dessa captura chega a ser desembarcada (Dp) e, dessa forma, a estimativa de rejeito ficou algo diferente das demais:

$$
R_{t}=\left(D_{c} \times c i p\right)-\left(D_{t}-D_{c}\right)
$$

onde cip corresponde à captura incidental de peixes como proporção da captura desembarcada de camarão considerada, no caso, 1,0 .

c) Indicação das principais áreas e épocas de pesca das espécies referidas, por tipo de pescaria.

A partir da definição dos principais componentes da captura de cada frota e estado, as espécies foram analisadas quanto à sazonalidade em cada região e ocorrência nas várias áreas de pesca. Tal análise foi efetuada a partir do conhecimento compilado por cada um dos participantes, em seus respectivos estados.

\section{d) Levantamento da legislação pesqueira refe- rente à pesca de arrasto}

Toda a legislação relativa à pesca de arrasto na região Sudeste-Sul, atualmente em vigor, foi extraída da coleção "Legislação Federal de Meio Ambiente", organizada por Waldir de Deus Pinto e editada pelo IBAMA (1996/ 2000). As portarias normativas foram ordenadas de acordo com suas finalidades e áreas de abrangência, como segue: a) limitação de esforço de pesca (controle de frota); b) regulamentação de petrechos (tamanho de malhas, restrições de uso); c) proteção de área (fechamento de área de pesca); d) limites de comprimento do indivíduo (tamanho mínimo); e) fechamento de estação de pesca (defesos). 


\section{RESULTADOS}

\section{a) Dimensão da Frota de Arrasteiros}

A partir da listagem de embarcações que efetuaram pelo menos um desembarque nos portos de Rio Grande, Itajai/Navegantes, Santos/Guarujá, Rio de Janeiro/Niterói e Vitória, foi realizada a quantificação do número aproximado de embarcações das categorias de arrasteiros, com exceção das embarcações de pequeno porte, por estas não terem seus desembarques regularmente monitorados na região como um todo.

De acordo com a tabela 2, encontramse em operação em toda a região Sudeste-Sul um total de 511 arrasteiros duplos, 163 arrasteiros de parelha e 11 arrasteiros simples, totalizando 685 embarcações de porte industrial.

Analisando-se a tabela 3, observa-se que existe um elevado grau de "fidelidade" das embarcações aos seus respectivos portos de origem, visto que somente uma parcela relativamente pequena de unidades realizou desembarques em mais de um estado do SudesteSul, no período considerado. Por exemplo, no caso dos portos de Santa Catarina e São Paulo, onde houve maior sobreposição das frotas, verifica-se que dos 401 arrasteiros duplos cujos desembarques foram registrados nestes estados, apenas 32 (aproximadamente $8 \%$ ) operaram em ambos, no período analisado. Compa- rativamente, pode-se observar ainda que, no caso das parelhas, o grau de fidelidade nos dois estados é ainda maior do que nos arrasteiros duplos, visto que somente uma parelha $(1,2 \%)$, dentre as 81 operantes em ambos, teve desembarques registrados nos dois portos.

\section{b) Estimativa da Composição da Captura Co- mercial e Rejeito}

A partir da matriz de desembarques por espécie, frota e estado (ANEXO 1), foram definidas cinco categorias de recursos: teleósteos, elasmobrânquios, crustáceos, cefalópodes, e mistura. A tabela 4 apresenta a composição dos desembarques (em te \%), por categoria, arte de pesca e estado, nos anos de 1998 e 1999 para todos os estados, menos RJ, onde os dados restringem-se ao ano de 1999.

Nos valores discriminados na tabela 4 , observa-se que tanto nos desembarques das parelhas como nos dos arrasteiros simples, os peixes teleósteos foram predominantes, atingindo percentuais entre 74 a $97 \%$, dependendo do estado.

No caso dos arrasteiros duplos, a composição dos desembarques foi relativamente similar para as embarcações que atuaram nos estados de Santa Catarina e Rio Grande do Sul, havendo o predomínio de teleósteos e camarões em proporções semelhantes. Entretanto, na frota de São Paulo observou-se uma par-

Tabela 2. Frota atuante no Sudeste e Sul do Brasil, por modalidade de arrasto, estado e período de desembarque.*

\begin{tabular}{l|c|c|c|c|c|c}
\hline \hline MODALIDADE & RS & SC & SP & RJ & ES & TOTAL \\
$(00)$ & $(00 \mathrm{a} 4 / 01)$ & $(00 \mathrm{a} 3 / 01)$ & $(99)$ & $(99)$ & \\
\hline Arrasto duplo & 64 & 308 & 93 & 111 & 49 & 529 \\
Parelha & 70 & 108 & 54 & 0 & 0 & 163 \\
Arrasto simples & 3 & 9 & 3 & 0 & 0 & 12 \\
\hline ** TOTAL & 137 & 425 & 150 & 111 & 49 & 704 \\
\hline \hline
\end{tabular}

*Cada um dos barcos que compõem as parelhas foi registrado separadamente.

** Embarcações que atuaram com duas modalidades de pesca foram computadas como duas unidades produtivas. $\mathrm{Na}$ totalização dos estados existem 12 barcos atuando com arrasto duplo e em parelha, 6 com arrasto duplo e simples e $1 \mathrm{com}$ arrasto simples e em parelha, resultando um total de 685 unidades produtivas, não repetidas, para o Sudeste-Sul do Brasil. 
Tabela 3. Unidades produtivas, por modalidade de pesca, que desembarcaram em dois ou mais estados, no período registrado.

\begin{tabular}{c|c|c}
\hline \multirow{2}{*}{ ESTADOS } & \multicolumn{2}{|c}{ MODALIDADE } \\
\cline { 2 - 3 } SC / SP & Arrasto duplo & Parelhas \\
SC / RS & 32 & 1 \\
SC / RJ & 8 & 17 \\
SC / ES & 2 & \\
SP / RJ & 2 & \\
SP / ES & 1 & \\
RJ / ES & 3 & \\
SC-SP-RS & 3 & 1 \\
SP / RS & & \\
\hline \hline
\end{tabular}

ticipação mais expressiva dos cefalópodes, enquanto no Rio de Janeiro houve a predominância absoluta dos teleósteos nos desembarques.

$\mathrm{Na}$ frota de pequeno porte, cabe destacar a participação dos crustáceos, os quais corresponderam a mais de $90 \%$ dos desembarques controlados nos estados de São Paulo, Paraná e Santa Catarina. Em contrapartida, tanto no Rio de Janeiro como no Espírito Santo, embora os crustáceos ainda tenham apresentado a maior importância, observou-se uma participação mais significativa dos peixes teleósteos e mesmo dos elasmobrânquios na composição dos desembarques.

As categorias taxonômicas acima foram discriminadas por espécie e ordenadas em ordem decrescente de importância, segundo os petrechos e estados, tendo sido consideradas apenas aquelas categorias cujos desembarques somados atingiram cerca de $90 \%$ do total registrado no período.

A tabela 5 mostra que, no caso das parelhas e dos arrasteiros simples, os cienídeos ainda constituem as principais espécies-alvo destas frotas, embora outros componentes como o peixe-porco e a abrótea, no caso das parelhas, e cabrinha e cações, nos arrasteiros simples, sejam relativamente importantes.

Em relação aos arrasteiros duplos, observa-se que os camarões barba-ruça e santana, linguado e abrótea lideram os desembarques das frotas de Santa Catarina e Rio Grande do Sul, sugerindo uma atuação conjunta das mesmas no litoral sul do Brasil. Por outro lado, outras espécies de importância nos arrasteiros de Santa Catarina se identificam com aquelas desembarcadas pela frota de São Paulo, sugerindo que as duas frotas também sobrepõem suas áreas de atuação em determinados períodos. Merece destaque o fato da frota paulista ser a única que, aparentemente, ainda mantém o camarão-rosa como principal espécie-alvo. Da mesma forma, chama a aten-

Tabela 4. Composição dos desembarques (em t e \%) das frotas de arrasto nos estados do Sudeste-Sul do Brasil, entre os anos de 1998 e 1999.

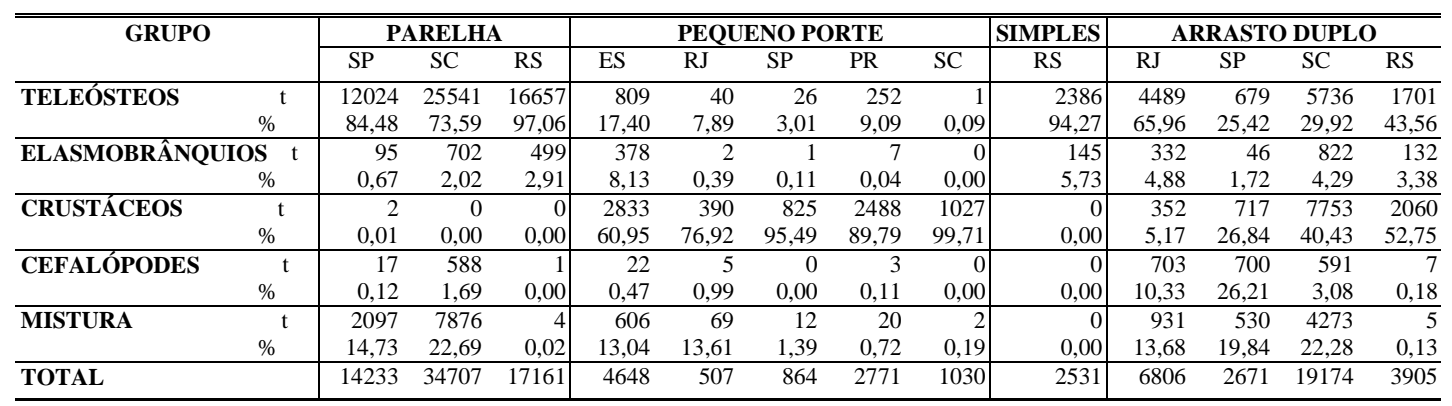

Obs.: os dados do Rio de Janeiro referem-se apenas ao ano de 1999. 
ção a captura altamente diversificada e diferenciada da frota do Rio de Janeiro, quando comparada com as demais frotas analisadas.

Comparando-se os desembarques das frotas de parelhas e arrasteiros simples com os dos arrasteiros duplos (incluindo-se neste grupo aqueles voltados à captura de camarões e os direcionados aos peixes demersais), observa-se que, no período considerado (19981999), a sobreposição entre as frotas foi relativamente pequena, principalmente considerando que os cienídeos não constituiram os principais elementos dos desembarques dos arrasteiros duplos, tendo sido substituidos por outras categorias de peixes, como o linguado, abrótea e cabrinha, além de diversos invertebrados como as lulas e polvos.

$\mathrm{Na}$ frota de pequeno porte, observa-se que os camarões sete-barbas e branco constituem as principais espécies-alvo em todos os estados, exceto no Espírito Santo onde o camarão-branco não apresenta importância significativa. Considerando que os desembarques do camarão-sete-barbas são muito superiores ao branco (ANEXO 1), pode-se concluir que a pesca de pequeno porte caracteriza-se por ser, praticamente, uma atividade mono-específica.

No ano de 2000, dados preliminares referentes aos desembarques no Rio Grande do Sul (CEPERG/IBAMA, dados não publicados) demonstram que não houve diferença significativa na composição das espécies, para as três frotas analisadas (parelhas, arrasteiros simples e duplos).

Por outro lado, em Santa Catarina (UNIVALI, dados não publicados) os desembarques dos arrasteiros duplos apresentaram, no ano de 2000, diferenças marcantes em relação aos anos anteriores, tendo predominado, em ordem decrescente de volume desembarcado, o camarão-barba-ruça, abrótea, cabrinha, camarão-santana, peixe-sapo, castanha, emplastro (raias da família Rajidae) e merluza. Especificamente, a presença de peixe-sapo, emplastro e merluza caracterizam uma recente migração da frota para a pesca em áre- as de talude. Adicionalmente, tem-se observado o gradativo desenvolvimento de uma frota de arrasto simples no Estado, cuja espéciealvo é também o peixe-sapo, com $63 \%$ do volume desembarcado, seguido pela abrótea de profundidade e merluza, evidenciando uma especialização de parte da frota para a pesca em áreas de plataforma externa e talude.

A análise dos desembarques efetuados pela frota de emalhe (ANEXO 2) permite verificar que, ao contrário do observado no arrasto, os elasmobrânquios constituíram uma parcela significativa da produção desta arte de pesca, respondendo por cerca de $25 \%$ do total registrado em São Paulo, 43\% em Santa Catarina e $11 \%$ no Rio Grande do Sul. Na tabela 5, da mesma forma que no arrasto, foram discriminadas as categorias de pescado que corresponderam a cerca de $90 \%$ dos desembarques da frota de emalhe. Atualmente, no Rio Grande do Sul, observa-se que esta pescaria tem os peixes cienídeos como os principais componentes dos desembarques, competindo, assim, com a pesca de arrasto na região. Por sua vez, o mesmo não ocorre em Santa Catarina e São Paulo, onde pode-se verificar um menor grau de sobreposição das respectivas espécies-alvo nos desembarques.

As estimativas de rejeição a bordo revelam que, em média, tanto os arrasteiros de pequeno porte como as parelhas e arrasteiros simples descartam cerca de $33 \%$ da captura total obtida nas respectivas viagens. No caso dos arrasteiros duplos, o percentual médio de rejeição é ligeiramente superior, situando-se ao redor de $45 \%$ da captura total (Tabela 6 ). Considerando-se as significativas modificações na dinâmica das pescarias de arrasto evidenciadas nos últimos anos, as quais incluem, por exemplo, o desembarque de espécies anteriormente não aproveitadas pela frota, é possível que os coeficientes de descarte utilizados para o cálculo das estimativas de rejeição (Tabela 1) tenham sofrido alterações ao longo do tempo. Desta forma, tais estimativas devem ser consideradas com cautela. 
PEREZ et al:: Ordenamento da Pesca de Arrasto no Sudeste-Sul do Brasil.

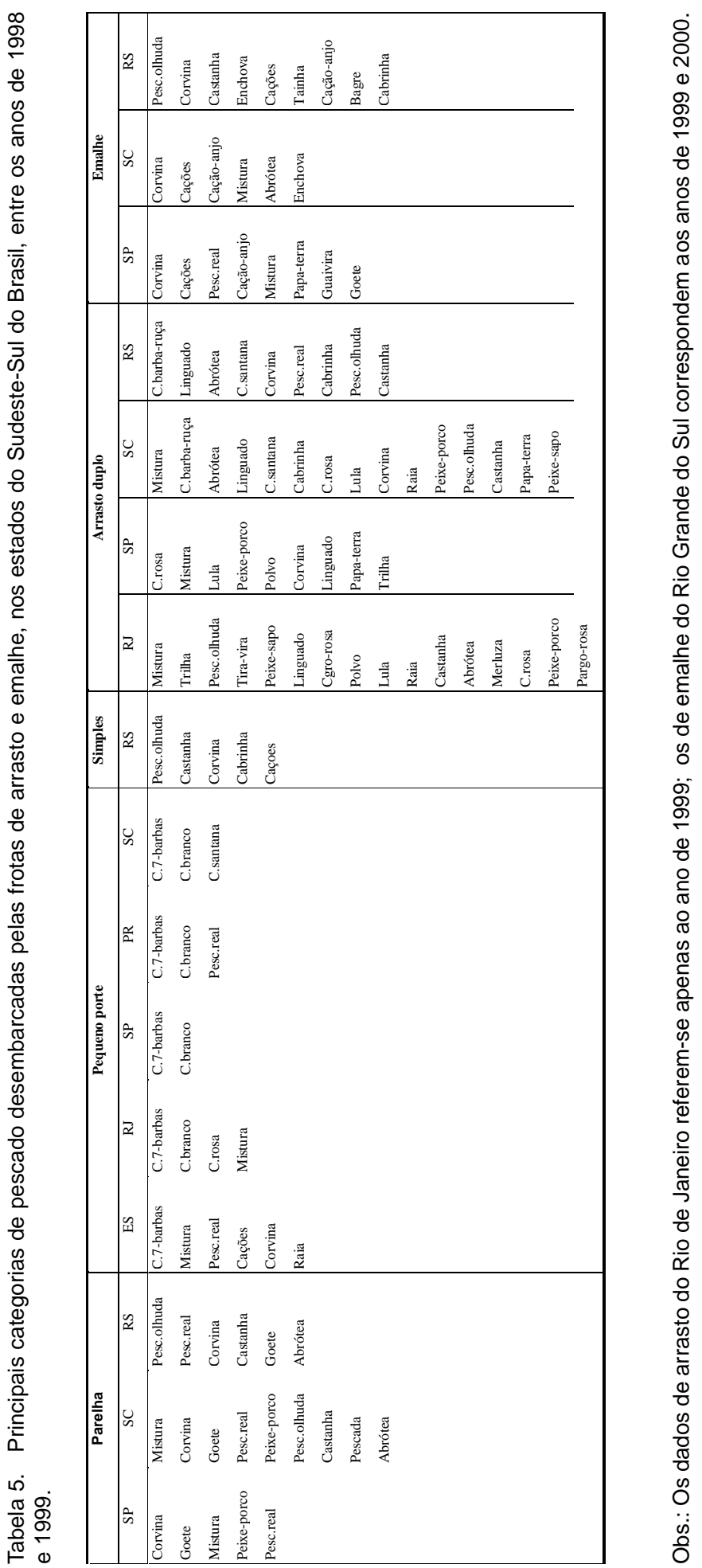




\section{c) Distribuição espacial e temporal das captu- ras}

Com base nas informações disponíveis na bibliografia, foi possível caracterizar quatro áreas principais de atuação da pesca de arrasto na região Sudeste-Sul do Brasil:

* Área costeira: abrange uma faixa praticamente contínua entre o norte do Espírito Santo e o sul de Santa Catarina, onde desenvolve-se uma pescaria concentrada, basicamente, na captura de camarões, principalmente do camarãosete-barbas (Valentini et al., 1991a).

* Plataforma Sul (costa do Rio Grande do Sul): nesta área, os arrasteiros simples e de pareIha têm como alvos principais os cienídeos pescada-olhuda, pescadinha-real, corvina e castanha, enquanto os arrasteiros duplos desenvolvem uma pescaria concentrada, principalmente, sobre os camarões barba-ruça e santana, além da abrótea, cabrinha e linguado (Kotas, 1991; Haimovici \& Mendonça; 1996; Haimovici, 1997).

* Plataforma Sudeste (sul de Santa Catarina até o norte de São Paulo): nesta região, as parelhas pescam, predominantemente, corvina, goete, pescadinha-real e peixe-porco. Por outro lado, os arrasteiros duplos capturam, principalmente, camarão-rosa, lulas, polvo, corvina e peixe-porco (Valentini et al., 1991b; 1991c; Kotas, 1991; Perez \& Pezzuto, 1998; Vianna, 1998; Castro, 2000; Tomás, dados não publi- cados).

* Plataforma externa e talude: em praticamente toda a extensão da costa Sudeste-Sul, vem sendo desenvolvida nos anos recentes uma nova pescaria de arrasto, particularmente a partir dos portos de Santa Catarina, tanto por arrasteiros duplos como por arrasteiros simples. Os alvos desta pescaria têm sido, principalmente, o peixe-sapo, a merluza, o congrorosa, raias e abrótea de profundidade. Eventualmente, observa-se o direcionamento dessas frotas também para invertebrados, como a lula (Illex argentinus), lagostim e camarão-cristalino (Perez \& Pezzuto, dados não publicados).

A distribuição temporal da ocorrência das principais espécies da plataforma continental do Sudeste-Sul nos desembarques está listada na tabela 7. Deve-se considerar que a sazonalidade observada nos padrões temporais de desembarque, além de refletirem variações na disponibilidade natural dos recursos, podem ser influenciados também pela própria dinâmica de deslocamento das frotas ao longo do ano, levando à maior ou menor captura de determinadas categorias, de acordo com a área de pesca explorada.

Em geral, verifica-se que a maior parte das espécies encontra-se disponível à pesca durante praticamente todo o ano, embora possam apresentar variações na sua abundância. $\mathrm{Na}$ área de pesca da Plataforma Sul, pode-se observar que os desembarques de cienídeos (exceto goête) e cações concentram-se, prin-

Tabela 6. Estimativas de captura total, desembarque e rejeição a bordo pelas frotas de arrasto nos estados do Sudeste-Sul do Brasil, entre os anos de 1998 e 1999.

\begin{tabular}{|c|c|c|c|c|c|c|c|c|c|c|c|c|}
\hline \multirow{2}{*}{$\begin{array}{c}\text { MODALIDADE } \\
\text { ESTADO }\end{array}$} & \multicolumn{3}{|c|}{ Parelha } & \multicolumn{5}{|c|}{ Pequeno porte } & \multirow{2}{*}{$\begin{array}{c}\text { Simples } \\
\text { RS }\end{array}$} & \multicolumn{3}{|c|}{ Arrasteiros duplos } \\
\hline & SP & $\mathrm{SC}$ & RS & ES & RJ & SP & PR & SC & & RJ & SP & $\mathrm{SC}$ \\
\hline Captura & 21350 & 52060 & 25742 & 5666 & 781 & 1650 & 4977 & 2053 & 3724 & 11802 & 9302 & 32430 \\
\hline Desembarque & 14233 & 34707 & 17161 & 4648 & 507 & 864 & 2771 & 1031 & 2531 & 6806 & 2671 & 19174 \\
\hline Rejeição total & 7117 & 17353 & 8581 & 1018 & 274 & 786 & 2206 & 1023 & 1193 & 4996 & 6631 & 13256 \\
\hline \% Rejeição & $33 \%$ & $33 \%$ & $33 \%$ & $18 \%$ & $35 \%$ & $48 \%$ & $44 \%$ & $50 \%$ & $32 \%$ & $42 \%$ & $71 \%$ & $41 \%$ \\
\hline
\end{tabular}

Obs.: os dados do Rio de Janeiro referem-se apenas ao ano de 1999. 
PEREZ et al:: Ordenamento da Pesca de Arrasto no Sudeste-Sul do Brasil.

Tabela 7. Períodos de maior ocorrência nos desembarques das prinicpais espécies capturadas pelas frotas de arrasto, nas plataformas Sul e Sudeste do Brasil.

\begin{tabular}{l|cccc}
\hline \multirow{2}{*}{$\begin{array}{l}\text { Plataforma Sul 1,2,3,4 } \\
\text { Camarões }\end{array}$} & \multicolumn{4}{|c}{ Ocorrência } \\
\cline { 2 - 4 } Cienídeos & Inverno & Primavera & Verão & Outono \\
\cline { 2 - 5 } Linguados & & $\mathrm{X}$ & $\mathrm{X}$ & $\mathrm{X}$ \\
Cabrinha & $\mathrm{X}$ & $\mathrm{X}$ & $\mathrm{X}$ & $\mathrm{X}$ \\
Abrótea & $\mathrm{X}$ & $\mathrm{X}$ & $\mathrm{X}$ & $\mathrm{X}$ \\
Cações & $\mathrm{X}$ & $\mathrm{X}$ & $\mathrm{X}$ & $\mathrm{X}$ \\
Cação-anjo & $\mathrm{X}$ & $\mathrm{X}$ & $\mathrm{X}$ & $\mathrm{X}$ \\
Goete & $\mathrm{X}$ & $\mathrm{X}$ & $\mathrm{X}$ & $\mathrm{X}$ \\
Polvo & & & $\mathrm{X}$ & $\mathrm{X}$ \\
& & & & \\
Plataforma Sudeste & & & $\mathrm{X}$ & $\mathrm{X}$ \\
Camarão-rosa & & & $\mathrm{X}$ & \\
Peixe-porco & & $\mathrm{X}$ & $\mathrm{X}$ & $\mathrm{X}$ \\
Lula & $\mathrm{X}$ & $\mathrm{X}$ & $\mathrm{X}$ & $\mathrm{X}$ \\
Polvo & & $\mathrm{X}$ & $\mathrm{X}$ & $\mathrm{X}$ \\
Corvina & $\mathrm{X}$ & $\mathrm{X}$ & $\mathrm{X}$ & \\
Outros cienídeos & $\mathrm{X}$ & & & \\
\hline
\end{tabular}

\author{
${ }^{1}$ Haimovici et al, 1989 \\ ${ }^{2}$ Haimovici \& Mendonça, 1996b \\ ${ }^{3}$ Haimovici, 1997 \\ ${ }^{4}$ Haimovici et al., 1997 \\ ${ }^{5}$ Valentini et al., 1991b \\ ${ }^{6}$ Valentini et al., 1991c \\ ${ }^{7}$ Kotas, 1991 \\ ${ }^{8}$ Perez \& Pezzuto, 1998 \\ ${ }^{9}$ Castro, 2000
}

cipalmente, nos meses de inverno e primavera. Já os de goête e polvo ocorrem com maior freqüência no verão e outono, enquanto os desembarques dos camarões santana e barbaruça são mais expressivos durante a primavera e o verão. Na Plataforma Sudeste, destacase apenas a concentração da captura das lulas nos meses de verão.

No que se refere à pesca de plataforma externa e talude, são poucas as informações disponíveis sobre a sazonalidade das pescarias, devido ao caráter recente do seu desenvolvimento. Os dados principais referem-se, fundamentalmente, a migrações sazonais de cações no talude do RS, especificamente de Carcharhinus signatus, abundante no verão, e de Squalus megalops, Squalus mitsukurii e Galeorhinus galeus, abundantes no inverno (Vooren et al., 1988).

Já na pesca costeira, embora apresentem variações temporais na sua abundância, os camarões sete-barbas e branco ocorrem durante todo o ano na região (Valentini et al., 1991a).

\section{d) Avaliação das Medidas de Ordenamento}

As portarias normativas em vigor nos estados da região Sudeste-Sul baixadas pelo IBAMA e voltadas, exclusivamente, ao ordenamento da pesca de arrasto estão relacionadas na tabela 8. Das 28 portarias atualmente vigentes, verifica-se que duas referem-se à limitação de tamanho das frotas de arrasteiros direcionados à captura dos camarões rosa e sete-barbas e de peixes demersais; duas tratam da definição de tamanhos mínimos de captura e duas definem períodos de defeso de camarões. As demais portarias tratam, principalmente, da regulamentação de petrechos, definição de áreas de pesca e, em especial, da limitação das áreas de atuação das embarcações de grande porte ao longo do litoral.

A análise dessas normas revela um nível relativamente elevado de regionalização do ordenamento, uma vez que apenas 8 abrangem, indistintamente, todos os estados da região Sudeste-Sul e uma tem âmbito nacional. As demais portarias são de âmbito estadual ou mesmo local, incidindo sobre lagoas ou baías em particular.

Cabe ressaltar que, desde a publicação da Medida Provisória no 1.999-17, de 11/04/ 2000 , os processos de licenciamento e renovação de licenças de pesca encontram-se sob a responsabilidade do Ministério da Agricultura, Pecuária e Abastecimento, através do Departamento de Pesca e Aqüicultura. Da mesma forma, o ordenamento das pescarias encontra-se dividido entre o IBAMA e o DPA/ 
Tabela 8. Portarias normativas do IBAMA/MMA de regulamentação do arrasto, nos estados das regiões Sudeste e Sul do Brasil.

\begin{tabular}{|c|c|c|c|c|c|c|c|c|}
\hline $\mathrm{N}^{\circ}$ & Ano & EMENTA & $\mathrm{A}$ & $\mathrm{B}$ & $\mathrm{C}$ & $\mathrm{D}$ & E & UF \\
\hline 575 & 1970 & $\begin{array}{l}\text { Regulamenta pesca de arrasto com portas nas baías de Paranaguá, } \\
\text { Guaratuba, Guaraqueçaba, Laranjeiras e Antonina, no litoral do PR }\end{array}$ & & $\mathrm{X}$ & & & & PR \\
\hline 602 & 1973 & $\begin{array}{l}\text { Regulamenta pesca de arrasto com portas na Baía de Guanabara } \\
\text { (RJ) }\end{array}$ & & $\mathrm{X}$ & & & & RJ \\
\hline 011 & 1982 & Proíbe arrasto em trecho (Coréia) do litoral de Vila Velha (ES) & & & $\mathrm{X}$ & & & ES \\
\hline 020 & 1983 & $\begin{array}{l}\text { Regulamenta pesca (área, potência motor e malha da rede) de } \\
\text { arrasto simples (popa) de camarões na Baía de Sepetiba (RJ) }\end{array}$ & & $\mathrm{X}$ & & & & RJ \\
\hline 051 & 1983 & $\begin{array}{l}\text { Proíbe arrasto (qualquer tipo) em trechos (baías, lagoas, etc.) no } \\
\text { litoral de SC }\end{array}$ & & & $\mathrm{X}$ & & & $\mathrm{SC}$ \\
\hline 026 & 1983 & $\begin{array}{l}\text { Regulamenta pesca (malha da rede) de arrasto no sudeste-sul e } \\
\text { proíbe arrasto a menos de } 3,0 \text { milhas da costa do RS }\end{array}$ & & $\mathrm{X}$ & $\mathrm{X}$ & & & $\begin{array}{l}\text { SE/SUL } \\
\text { (RS) }\end{array}$ \\
\hline 057 & 1983 & Altera Port. 026/83 (altera prazo) & & & & & & SE/SUL \\
\hline 062 & 1984 & $\begin{array}{l}\text { Proíbe arrasto (emb.>10 TAB) a menos de 3,0 milhas e 1,0 milha } \\
\text { (emb.<10 TAB) da costa do PR }\end{array}$ & & & $\mathrm{X}$ & & & PR \\
\hline 055 & 1984 & $\begin{array}{l}\text { Estabelece tamanho mínimo (indivíduo) e regulamenta uso de } \\
\text { petrechos (aviãozinho, caceio e arrasto) na pesca de camarões-rosa e } \\
\text { verdadeiro no sudeste-sul }\end{array}$ & & $\mathrm{X}$ & & $\mathrm{X}$ & & SE/SUL \\
\hline 056 & 1984 & $\begin{array}{l}\text { Regulamenta uso de petrechos (arrastão de porta) na pesca de } \\
\text { arrasto de camarões } 07 \text { barbas no sudeste-sul }\end{array}$ & & $\mathrm{X}$ & & & & SE/SUL \\
\hline 054 & 1984 & $\begin{array}{l}\text { Proíbe arrasto (emb.>10 TAB) a menos de 1,5 milhas da costa de } \\
\text { SP }\end{array}$ & & & $\mathrm{X}$ & & & SP \\
\hline 075 & 1985 & Proíbe arrasto de fundo na baía de Vitória (ES) & & & $\mathrm{X}$ & & & ES \\
\hline 003 & 1987 & Proíbe arrasto de portas/parelhas em trechos do litoral do RJ & & & $\mathrm{X}$ & & & RJ \\
\hline 445 & 1989 & Altera Portarias $026 / 83$ (altera prazo) & & & & & & SE/SUL \\
\hline 784 & 1990 & $\begin{array}{l}\text { Proíbe arrasto (emb.>10 m) a menos de 2,5 milhas em trecho do } \\
\text { litoral (Mar do Rio Doce) do ES }\end{array}$ & & & $\mathrm{X}$ & & & ES \\
\hline 107 & 1992 & $\begin{array}{l}\text { Proíbe arrasto de portas/parelhas (emb.>10 TAB) a menos de } 3,0 \text { e } \\
1,0 \text { milhas em trechos da costa de SC }\end{array}$ & & & $\mathrm{X}$ & & & $\mathrm{SC}$ \\
\hline 112 & 1992 & $\begin{array}{l}\text { Proíbe arrastão de praia com malha inferior a } 70 \mathrm{~mm} \text { em águas } \\
\text { costeiras de SC }\end{array}$ & & $\mathrm{X}$ & & & & $\mathrm{SC}$ \\
\hline 133 & 1994 & Estabelece defeso de camarões nas baías do PR & & & & & $\mathrm{X}$ & PR \\
\hline 135 & 1994 & $\begin{array}{l}\text { Regulamenta pesca (uso de petrechos, inclui arrasto) em áreas } \\
\text { estuarinas e lagunares no PR }\end{array}$ & & $\mathrm{X}$ & & & & PR \\
\hline 043 & 1994 & $\begin{array}{l}\text { Proíbe arrasto de porta/parelha (emb.>10 TAB) a menos de } 2,0 \\
\text { milhas da costa do RJ }\end{array}$ & & & $\mathrm{X}$ & & & RJ \\
\hline 026 & 1995 & $\begin{array}{l}\text { Regulamenta pesca da tainha (inclui arrasto de praia) nos costões do } \\
\text { litoral de SC }\end{array}$ & & $\mathrm{X}$ & & & & $\mathrm{SC}$ \\
\hline 005 & 1997 & $\begin{array}{l}\text { Determina uso obrigatório do TED (Turtle Excluder Device) pela } \\
\text { frota camaroneira em todo o litoral do Brasil }\end{array}$ & & $\mathrm{X}$ & & & & $\mathrm{BR}$ \\
\hline 095 & 1997 & $\begin{array}{l}\text { Limita frota de arrasto de peixes (corvina, pescada, etc......) no } \\
\text { litoral sudeste-sul }\end{array}$ & $\mathrm{X}$ & & & & & SE/SUL \\
\hline 097 & 1997 & Limita frota de arrasto de camarões no litoral sudeste-sul & $\mathrm{X}$ & & & & & SE/SUL \\
\hline 027 & 1999 & $\begin{array}{l}\text { Regulamenta pesca (tipos de petrecho, inclui rede de coca -tipo de } \\
\text { arrasto) na Lagoa do Camacho, em SC }\end{array}$ & & $\mathrm{X}$ & & & & $\mathrm{SC}$ \\
\hline 054 & 1999 & $\begin{array}{l}\text { Regulamenta uso de rede (emalhar e arrasto de praia) no litoral de } \\
\text { SC }\end{array}$ & & $\mathrm{X}$ & & & & $\mathrm{SC}$ \\
\hline 013 & 2000 & $\begin{array}{l}\text { Regulamenta pesca (tipos de petrecho, tamanho mínimo de } \\
\text { indivíduo, proíbe arrasto) de camarões (rosa e branco) na Baía de } \\
\text { Babitonga, em SC }\end{array}$ & & $\mathrm{X}$ & & $\mathrm{X}$ & & $\mathrm{SC}$ \\
\hline 074 & 2001 & Estabelece defeso (pesca de arrasto) de camarões no sudeste-sul & & & & & $\mathrm{X}$ & SE/SUL \\
\hline
\end{tabular}

A - limitação de esforço de pesca (controle de frota)

B - regulamentação de petrechos (tamanho de malhas, restrições de uso)

C - proteção de área (fechamento de área de pesca)

D - limites de comprimento do indivíduo (tamanho mínimo)

E - fechamento de estação de pesca (defesos)

OBS.:A Portaria 074/2001 foi editada pelo Ministério do Meio Ambiente. As demais pelo IBAMA 
MAPA, segundo o nível de explotação dos respectivos recursos. Recursos considerados sobreexplotados ou em vias de sobreexplotação têm o seu ordenamento a cargo do IBAMA, enquanto as espécies consideradas não explotadas, subexplotadas e altamente migratórias encontram-se sob a responsabilidade do DPA/MAPA. Nesse sentido, pode-se adicionar ao conjunto de medidas de ordenamento da pesca de arrasto listadas na tabela 8 , a Instrução Normativa no. 10 (DPA/MA), de 09/10/2000, que limita a atuação de embarcações estrangeiras arrendadas que operam na modalidade de arrasto de fundo à profundidade mínima de 200 metros.

\section{CONCLUSÕES}

A partir das conclusões principais das duas reuniões de ordenamento dos recursos demersais, realizadas no ano 2000 (ANEXOS 3 e 4), e das informações consolidadas na presente reunião, pode-se assumir, inicialmente, que a pesca na área costeira permanece no seu padrão tradicional, sendo dirigida a uma espécie-alvo principal, o camarão-sete-barbas. Quanto à pesca de plataforma, prevalece, na atualidade, um estado de desordenamento das pescarias, visto que a situação de plena explotação, ou mesmo de sobreexplotação da maioria dos estoques tem levado as embarcações de médio e grande porte a não mais se limitarem à captura dos recursos para os quais estão permissionadas. A percepção de que a quantidade de rejeito tem diminuído e que a categoria "mistura" aparece como um dos principais itens no desembarque das várias modalidades, em toda a região, indicam sinais claros de exaustão dos recursos tradicionais.

Como exemplo, pode-se observar que a frota industrial de camaroneiros não mais se sustenta apenas da captura do camarão-rosa e sim, também, do aproveitamento de espécies comerciáveis da fauna acompanhante e/ou do direcionamento do seu esforço a recursos disponíveis ao arrasto, mas não necessariamente componentes do bycatch do camarão-rosa. Tal fato tem levado a que, à exceção do observado na frota de São Paulo, o camarão-rosa não mais se caracterize, de forma bem definida, como uma espécie-alvo nas capturas.

Em decorrência desta situação, já não se observa, na prática, uma discriminação clara das capturas efetuadas pela frota de arrasteiros duplos licenciada para a pesca de camarão-rosa e fauna acompanhante, daquela licenciada para captura de peixes demersais, caracterizando, assim, uma única pesca de arrasto multiespecífica.

Tal fato tem implicado em:

* um aumento desordenado e oportunista do esforço de pesca sobre recursos de plataforma já plenamente explotados, ou mesmo sobreexplotados. Dentre estes, incluem-se espécies componentes da fauna acompanhante do camarão-rosa (lulas, vieira, linguado, peixeporco, etc.), que, eventualmente, se transformam em espécies-alvo nesta pescaria, e também estoques disponíveis à pesca de arrasto mas que não se caracterizam como bycatch do camarão (p.ex., camarões santana e barba-ruça);

* um crescente direcionamento do esforço para recursos anteriormente não explotados, principalmente nas áreas de plataforma externa e talude, de forma igualmente concentrada, e cujo potencial de sustentabilidade ainda é desconhecido (peixe-sapo, congro-rosa, emplastro, lagostim, etc.).

Além da situação de sobreexplotação dos recursos tradicionais, oportunidades de mercado e variações temporais na disponibilidade de certas espécies, têm gerado verdadeiras "corridas do ouro" (Perry et al., 1999), ou seja, explotações oportunistas extremamente localizadas no tempo e no espaço. Considerando o nível de sobredimensionamento da frota, este fato colabora para depleções localizadas e incontroláveis de recursos ou, pelo me- 
nos, para a diminuição rápida da abundância de várias espécies. Como exemplo típico, podese destacar o caso da vieira Euvola ziczac, a qual foi intensamente capturada pela frota camaroneira industrial de São Paulo e Santa Catarina nas décadas de 1970 e início de 1980, como resposta ao incremento da demanda internacional pelo produto e à queda pronunciada nos rendimentos do camarão-rosa. Nesse período, ocorreram dois picos de produção. $\mathrm{O}$ primeiro, entre 1973 e 1975, gerou capturas anuais máximas da ordem de 3.800 toneladas, sendo seguido por anos de baixa produção. Entre 1979 e 1981 houve o segundo e maior pulso de produção, o qual atingiu cerca de 8.800 toneladas em 1980. Após este período, a pescaria entrou em colapso e não se recuperou até o momento, sendo que, nos últimos seis anos, as capturas registradas no Sudeste e Sul do Brasil não ultrapassaram algumas centenas de quilos (Pezzuto \& Borzone, 1997; Pezzuto, 2001). Outras pescarias similares já foram identificadas ao longo do tempo com risco similar de depleção, caso sejam mantidos os níveis de esforço observados. Dentre estas, pode-se citar os casos da lula (Perez, no prelo), lagostim (Rodrigues, 1997), peixe-sapo e raias da família Rajidae (CEPSUL/IBAMA, 2001). Outro fato a ser destacado é a possibilidade de sobrepesca em espécies capturadas exclusivamente como pescado acidental do arrasto camaroneiro, cujo manejo só pode ser feito pela administração multiespecifica (Vianna, 1988; Vianna et al., 2000).

O caráter atualmente multiespecífico desta pescaria, em que os diversos recursos vão sucessivamente tornando-se alvo de forma dinâmica e efêmera, agrava-se ainda mais face à clara existência de sobreposição das capturas das frotas de arrasto com outras frotas atuantes na região Sudeste-Sul. No caso dos arrasteiros direcionados aos peixes demersais, há uma evidente sobreposição das suas capturas com aquelas obtidas pela frota de emalhe, principalmente na área de pesca da Plataforma Sul. Nesta região, desde 1995, a pesca de emalhe de cações em áreas profundas deixou de ser rentável e redirecionou-se para a captura de cienídeos na plataforma interna (Haimovici, em preparação; Tomás, submetido). A considerar as perspectivas de redução dos estoques de cações, ainda utilizados como recursos-alvo do emalhe em Santa Catarina, pode-se prever que, cada vez mais, a atual superposição existente entre as capturas destas frotas venha a ser observada em toda a região Sudeste-Sul, induzindo à necessidade de que tais pescarias sejam ordenadas de maneira conjunta.

Por outro lado, a partir do exposto no ANEXO 3, verifica-se que a frota de arrasto nacional vem atuando, progressivamente, sobre recursos de plataforma externa e talude que, em parte, ainda encontram-se subexplotados. Entretanto, para tais recursos, sob jurisdição do DPA/MAPA, já existe uma política de explotação, embasada no arrendamento de embarcações estrangeiras de elevado poder de pesca, caracterizando, assim, uma nova situação de sobreposição de frotas e incremento descontrolado de esforço sobre tais estoques. Legalmente, as embarcações tradicionais, principalmente as camaroneiras, não poderiam estar atuando nas áreas de talude, em razão de seu licenciamento específico. A atuação desta frota, cujo ordenamento é feito pelo IBAMA, em conjunto com a da frota arrendada, controlada pelo DPA, pode gerar, na prática um conflito de responsabilidades na aplicação de medidas de manejo sobre os recursos envolvidos, bem como conflitos de uso entre as duas, a exemplo do já observado entre a frota nacional de arrasto e a frota arrendada de emalhe licenciada para captura do peixe-sapo no Rio de Janeiro (SAPERJ, 2001).

Em parte, o quadro acima descrito reflete o processo de falência do modelo de gestão da pesca de arrasto do Sudeste-Sul do Brasil. Considerando a multiespecificidade da pesca de arrasto de plataforma, fica claro que o modelo de manejo baseado na proteção de espécies-alvo tradicionais não parece mais se justificar nessa região. Apenas a pesca na Área Costeira permanece, basicamente, no seu pa- 
drão tradicional, sendo dirigida a uma única espécie-alvo, o camarão-sete-barbas, o que ainda justificaria a manutenção da estratégia de manejo baseada na proteção do estoquealvo.

Entretanto, os períodos de desova do camarão-sete-barbas no Sudeste-Sul abrangem os meses de primavera e verão (Vieira, 1947; Santos et al., 1969; Severino Rodrigues et al., 1993; Nakagaki \& Negreiros-Fransozo, 1998; Branco et al., 1999), não estando, portanto, protegidos pelo defeso de recrutamento do camarão-rosa ao qual o recurso está submetido. Além disso, estudos demonstram que os melhores rendimentos do camarão setebarbas são obtidos justamente no período que engloba a paralisação da pescaria de camarões em mar aberto (SUDEPE/PDP, 1983; Branco et al., 1999; Borzone, 2001). A própria comunidade de pescadores artesanais tem cobrado, por isso, um defeso específico para esta espécie, fato este já reportado na Reunião Técnica sobre Camarões das Regiões Sudeste e Sul do Brasil, realizada em Itajaí/ SC em 1993 (CEPSUL/IBAMA, 1993).

Além dos problemas ocasionados à pescaria do camarão-sete-barbas na Área Costeira, o defeso do camarão-rosa não tem sido eficaz para a própria sustentabilidade deste recurso, nas áreas de plataforma. Na maioria das edições anuais do defeso, tem sido permitida a atuação das embarcações camaroneiras industriais tanto sobre as espécies acompanhantes do camarão como sobre outros recursos, levando não só a uma captura inegável e ilegal do camarão-rosa neste período, como também à elevação do esforço de pesca sobre estoques de peixes sob controle. Ademais, a intensa pesca artesanal do camarão-rosa nas áreas de criadouro tem fundamental influência na abundância do estoque reprodutor marinho. Caso essa atividade não seja ordenada, não há perspectiva de recuperação desse estoque (Valentini et al., 1991c).

No caso das frotas de tangones e pareIhas dirigidas à captura de peixes demersais, sua regulamentação se restringe, basicamen- te à proibição da concessão de novas licenças e definição de um tamanho mínimo de malha no ensacador. Da mesma forma, as pescarias de peixes demersais encontram-se seriamente comprometidas (Gasalla \& Tomás, 1998). Uma análise recente das capturas demonstra que: $4 \%$ dos desembarques provêm dos estoques já exauridos de quatro espécies; $37 \%$ de quatro espécies sobreexplotadas; $24 \%$ de duas espécies plenamente explotadas e $35 \%$ de estoques com situação incerta (Haimovici, 1998).

O censo das embarcações mostra a existência de, pelo menos, 511 arrasteiros duplos operando no Sudeste-Sul, potencialmente sobre os mesmos recursos. Tal número é claramente superior ao tamanho de frota compatível com a sustentabilidade dos mesmos, a exemplo do observado com o camarão-rosa (Valentini et al., 1991c). Situação semelhante é observada na pesca de peixes demersais efetuada pelas parelhas, onde os rendimentos têm declinado progressivamente ao longo do tempo (Haimovici, 1998). Parece claro que esse tamanho de frota não se sustentará, considerando-se o estado de explotação dos recursos de plataforma, o que sugere uma progressiva redução na rentabilidade destas pescarias, em curto prazo.

As únicas alternativas para se alcançar a necessária redução do esforço de pesca na região seriam:

* redução do número de embarcações atuantes;

* direcionamento da frota para áreas pouco exploradas (porém, com o cancelamento das atuais licenças e efetiva desvinculação das mesmas aos recursos tradicionais);

* implementação de modificações tecnológicas nas redes através da utilização de Bycatch Reduction Devices ou,

* a melhor repartição do esforço sobre os recursos remanescentes. 
A primeira opção parece ser a de adoção mais difícil, devido ao maior impacto sócio-econômico. A segunda, apesar de levar a uma redução do esforço na plataforma, pode incorrer num incremento desordenado do mesmo sobre estoques não dimensionados, implicando na transferência do problema atual para novas áreas. A terceira depende de resultados de pesquisas ainda em andamento e a quarta requer, basicamente, a mudança na filosofia do ordenamento, buscando organizar a distribuição do esforço de pesca nas áreas de plataforma, de maneira compatível com a sustentabilidade dos vários estoques envolvidos.

O nível de conhecimento atual sobre a localização e disponibilidade temporal dos recursos permite identificar, claramente, ao longo da região Sudeste-Sul, a existência de áreas de pesca relativamente distintas. Tais informações, associadas com a disponibilidade de tecnologia acessível para o monitoramento da frota, abrem caminho para a adoção de um novo modelo de ordenamento, baseado no estabelecimento de áreas distintas de explotação e no controle efetivo das frotas permissionadas para atuarem nas mesmas.

\section{MODELO DE ORDENAMENTO DAS PES- CARIAS DE ARRASTO E EMALHE DO SUDESTE- SUL DO BRASIL}

A partir das conclusões acima enunciadas, torna-se evidente a necessidade de subdividir as pescarias de arrasto e emalhe nas regiões Sudeste e Sul em duas categorias básicas, para efeito de manejo:

a) Pesca costeira: sustentada, basicamente, pela captura do camarão sete-barbas, é desenvolvida, em sua maior parte, por embarcações de pequeno porte em áreas relativamente rasas da plataforma continental, desde o Espírito Santo até Santa Catarina.

b) Pesca de alto mar: caracterizada como uma pescaria eminentemente multiespecífica, é realizada por embarcações de médio e grande porte, nos demais setores da plataforma continental e talude de todos os estados da região Sudeste-Sul.

De acordo com tal subdivisão, foi elaborada proposta preliminar de um novo modelo de manejo, para cada uma das categorias acima.

\section{a) Pesca costeira}

Para a pesca costeira, considerou-se, fundamentalmente, o fato de que a mesma continua apresentando uma característica monoespecífica, podendo-se discriminar, ao longo de toda a região (exceto no Rio Grande do Sul), uma única espécie-alvo, para cuja proteção o manejo deve ser direcionado. Adicionalmente, cabe destacar que esta pescaria tem, em grande parte, características semi ou totalmente artesanais, o que, se por um lado reforça sua forte vinculação com comunidades litorâneas, por outro limita as opções disponíveis para seu acompanhamento, com vistas ao manejo.

Desta forma, propõe-se que o manejo da Pesca Costeira seja norteado pelos seguintes termos:

* Sistema de licenciamento unificado para toda a região Sudeste-Sul, com a opção de limitação do acesso à pescaria;

* Manutenção da legislação atual, que define os limites das áreas de atuação da frota de arrasto em cada estado;

* Estabelecimento de medidas de manejo específicas para o camarão sete-barbas, incluindo a definição de um período de defeso desvinculado daquele dirigido ao camarão-rosa, preferencialmente entre os meses de outubro e dezembro.

* Regionalização do ordenamento, mediante 
processo de gestão participativa, com o envolvimento dos pescadores através das suas entidades representativas, nas tomadas de decisão para o manejo sustentável da pescaria.

\section{b) Pesca de alto mar}

Ao contrário do observado na pesca costeira, a pesca de alto mar apresenta características fundamentalmente multiespecíficas, sendo necessária a implementação de um sistema de manejo de frotas e não apenas de recursos pesqueiros, de forma isolada. Além disso, há uma clara necessidade de redução do esforço de pesca, a qual, não sendo possível pela retirada imediata de embarcações, poderia ser obtida através da otimização da distribuição do esforço já existente ao longo da região. Tal fato demanda uma regionalização do manejo, via alocação de licenças e estabelecimento de medidas de ordenamento específicas por área de pesca, embasados no conhecimento científico disponível sobre os estoques envolvidos. Adicionalmente, em substituição ao livre acesso aos recursos, propõe-se uma modificação na forma de aquisição e renovação de licenças, visando à introdução de um indispensável sentido de propriedade sobre os recursos, no sentido de incentivar o cumprimento das medidas de manejo e facilitar a fiscalização. Especialmente no que tange ao controle da frota e da própria pescaria, foram considerados os novos avanços tecnológicos atualmente disponíveis para este fim, os quais, inclusive, já estão sendo utilizados na Zona Econômica Exclusiva Brasileira (UNIVALI-MA, 2001).

Considerando tais aspectos, propõe-se os seguintes elementos para o ordenamento da pesca de alto mar na região Sudeste-Sul:

* Estabelecimento de seis áreas de explotação (Fig. 1) definidas, batimetricamente, pela isóbata de 100 metros e, latitudinalmente, pelo limite dos estados do Espírito Santo e Bahia e
Cabo Frio/RJ (áreas I e II); Cabo Frio/RJ e Torres/RS (áreas III e IV); Torres/RS e Arroio Chuí/ $\mathrm{RS}$ (áreas V e VI);

* Definição das mesmas como áreas de manejo para as pescarias de arrasto e de emalhe, a serem administradas de forma específica, considerando as informações disponíveis sobre os principais estoques comerciais e a fauna acompanhante;

* Substituição total do modelo vigente de licenciamento das frotas de arrasteiros e de emalhe, o qual passaria a ser executado através da alocação de um número limitado de licenças por área de explotação, definido a partir das recomendações de um Grupo Técnico Regional de Avaliação de Estoques, e de acordo com as características de sustentabilidade dos respectivos estoques. As licenças deverão ser outorgadas, anualmente, mediante leilão público e com valores mínimos estipulados segundo as características das próprias áreas, em termos de produtividade e valor econômico dos recursos;

* Definição de medidas de ordenamento específicas para cada área de explotação, também seguindo recomendações do Grupo Técnico, conforme as particularidades dos recursos envolvidos;

* Obrigatoriedade de instalação, em todas as embarcações, de Sistema de Rastreamento por Satélite, com características que atendam aos critérios mínimos de funcionalidade definidos pelo Grupo Técnico e pelos setores de fiscalização do IBAMA e DPA/MAPA. Tal sistema deverá permitir não só a fiscalização do uso das áreas como, também, a captação de informações estatísticas da pesca em tempo real. 


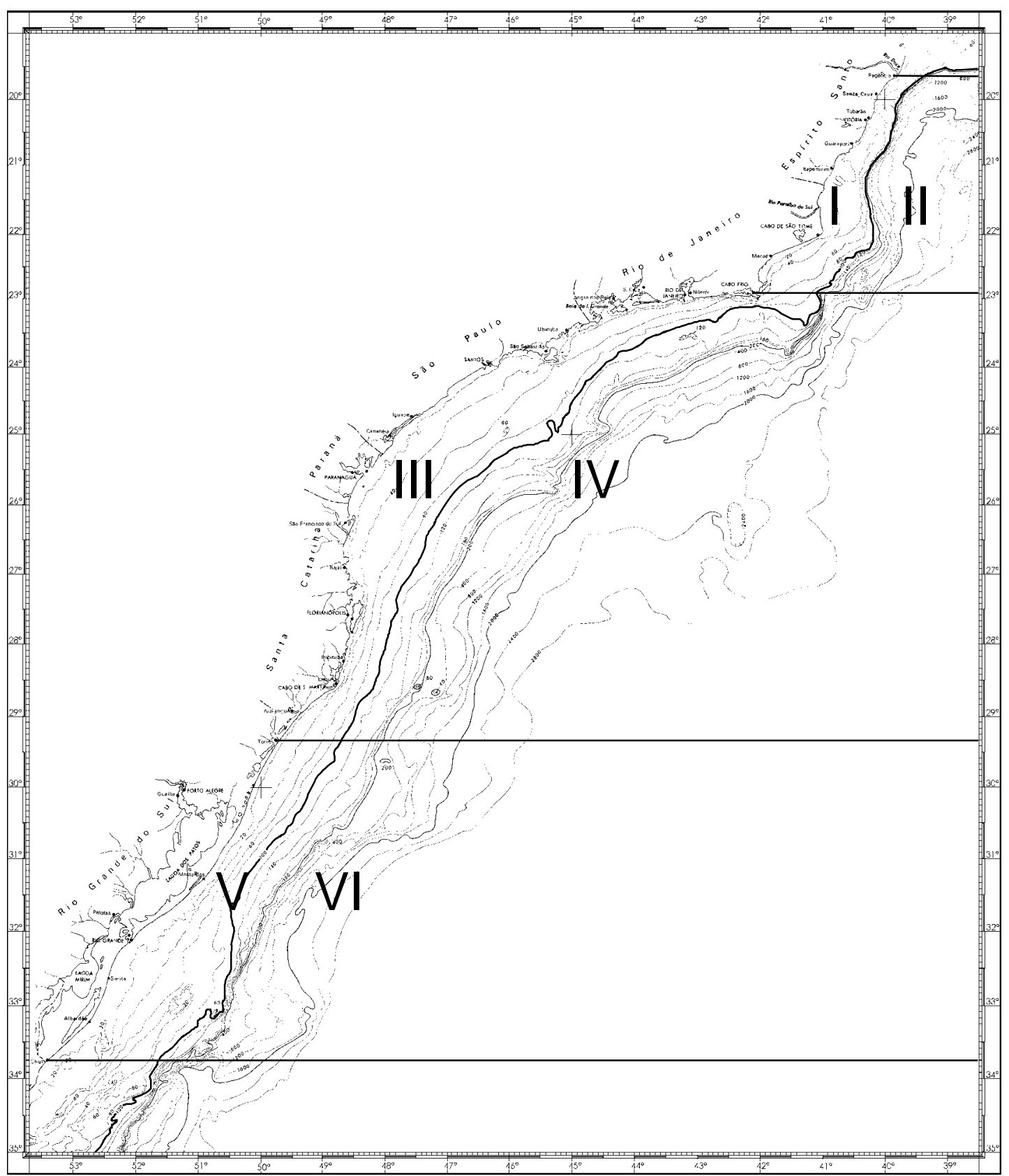

Figura 1. Áreas de explotação para a pesca de arrasto e emalhe no Sudeste-Sul do Brasil. Limite batimétrico: isóbata de 100 metros. 


\section{CONSIDERAÇÕES FINAIS}

Face ao exposto, é posição unânime de um grupo representativo dos pesquisadores do Sudeste-Sul do Brasil envolvidos com a pesca demersal, de que o modelo de ordenamento vigente na região não mais se sustenta. Os recursos pesqueiros vêm sofrendo declínios evidentes de abundância, inclusive com situações claras de colapso de alguns estoques. Mantido o atual modelo, é certo que os poucos recursos ainda subexplotados da região (sobretudo aqueles localizados nos setores mais externos da ZEE) trilharão caminho similar, reduzindo as alternativas de médio e longo prazo para a manutenção de um nível adequado de sustentabilidade da pesca demersal no Sudeste-Sul do País.

O novo modelo proposto foi considerado pelo Grupo como a melhor alternativa possível para a busca de reversão do quadro atual. $A$ manutenção de iniciativas de pouco impacto efetivo, como a negociação de datas e modos de implementação dos defesos, ajustes de tamanho de malhas, tamanhos mínimos de captura, etc., tal como foram desenvolvidas nos últimos anos, é vista como ineficaz e improdutiva.

Deste modo, entende-se como imprescindível que o IBAMA e o DPA/MAPA, em conjunto, considerem objetivamente tal proposta e envidem esforços para que o novo modelo possa ser implementado.

\section{REFERÊNCIAS BIBLIOGRÁFICAS}

Alverson, D. L.; Freeberg, M. H.; Murawski, S. A. \& J. G. Pope. 1994. A global assessment of fisheries bycatch and discards. FAO Fish. Tech. Pap. 339, 233 p.

Borzone, C. A. 2001. O atual manejo da pesca do camarão no litoral sudeste-sul do Brasil e os seus efeitos na atividade pesqueira artesanal. Anais do IX Congresso
Latinoamericano de Ciencias do Mar. No prelo.

Branco, J. O.; Lunardon-Branco, M. J.; Souto, F. X. \& C. R. Guerra. 1999. Estrutura populacional do camarão sete-barbas Xiphonenaeus kroyeri (Heller, 1862), na foz do Rio Itajaí-Açú, Itajaí, SC, Brasil. Brazil. Arch. Biol. Technol., 42(1):115-126.

Castro, P. M. G. 2000. Estrutura e dinâmica da frota de parelhas do Estado de São Paulo e aspectos biológicos dos principais recursos pesqueiros demersais costeiros da região Sudeste/Sul do Brasil (23( - 29( S). Tese de Doutorado, Instituto Oceanográfico da Universidade de São Paulo, SP.

CEPSUL/IBAMA. 1993. Relatório da reunião técnica sobre camarões das regiões Sudeste e Sul do Brasil. Itajaí - SC, 04 a 08 de outubro de 1993.

CEPSUL/IBAMA. 2001. Reunião técnica sobre o estado atual da arte e ordenamento da pesca de peixes demersais nas regiões Sudeste e Sul. Itajaí - SC, 04 a 08 de dezembro de 2000, $37 p$.

Gasalla, M.A. \& A.R.G. Tomás 1998 Evaluation of the status of fisheries data collection and stock assessment problems in São Paulo, Southeastern Brazil, p. 41-60. In: Funk, F.; Quinn II, T.J.; Heifetz, J.; Ianelli, J.N.; Powers, J.E.; Schweigert, J.F.; Sullivan, P.J. \& C.I. Zhang (Eds.). Fishery Stock Assessment Models. Alaska Sea Grant College Program Report no. AK-SG-98-01, University of Fairbanks.

Graça-Lopes, R. 1996. A pesca do camarão sete-barbas Xiphopenaeus kroyeri Heller (1862) e sua fauna acompanhante no litoral do Estado de São Paulo. Tese de Doutorado. Universidade Estadual Paulista, Instituto de Biociências de Rio Claro.

Haimovici, M. 1997. Recursos pesqueiros demersais da Região Sul. REVIZEE FEMAR, Rio de Janeiro - RJ.

Haimovici, M. 1998. Present state and perspectives for the southern Brazil shelf 
demersal fisheries. Fisheries Management and Ecology, 5:277-289.

Haimovici, M.; S. Pereira \& P. C. Vieira. 1989. La pesca demersal en el sur de Brasil en el período 1975-1985. Frente Marítimo, 5(Sec. A):151-163.

Haimovici, M.; Castello, J. P. \& C. M. Vooren. 1997. Fisheries, p. 183-196. In: Seeliger, U.; Odebretch, C. \& J. P. Castello (Eds.). Subtropical Convergence Environments: the Coastal and Sea in the Southwestern Atlantic. Springer.

Haimovici, M. \& J. T. Mendonça. 1996a. Descartes na pesca de arrasto de tangones dirigida ao linguado e ao camarão no sul do Brasil. Atlântica, Rio Grande, 18:161177.

Haimovici, M. \& J. T. Mendonça. 1996b. Análise da pesca de tangones de peixes e camarões no sul do Brasil. Atlântica, Rio Grande, 18:143-160.

Haimovici, M. \& R. Palacios Maceira. 1981. Observações sobre a seleção a bordo e rejeição na pesca de arrasto de fundo no Rio Grande do Sul. Anais do II Congresso Brasileiro de Engenharia de Pesca, Recife, PE, julho de 1981.

Kotas, J. E. 1998. Fauna acompanhante nas pescarias de camarão em Santa Catarina. IBAMA, DF. Coleção Meio Ambiente, Série Estudos Pesca 24.

Nakagaki, J. M. \& M. L. Negreiros-Fransozo. 1998. Population biology of Xiphopenaeus kroyeri (Heller, 1862) (Decapoda: Penaeidae) from Ubatuba bay, São Paulo, Brazil. J. Shellfish Res., 17(4): 931-935.

Paiva-Filho, A. M. \& J. M. M. Schimiegelow. 1986. Estudos sobre a ictiofauna acompanhante da pesca do camarão sete-barbas (Xiphopenaeus kroyeri) nas proximidades da Baia de Santos-SP. I - Aspectos quantitativos. Bolm. Inst. Oceanog. S. Paulo, 34: 79-85.

Perez, J. A. A. 2000. Biomass dynamics of the squid Loligo plei and the development of a small-scale fishery off southern Brazil. Bull. Mar. Sci. No prelo.

Perez, J. A. A. \& P. R. Pezzuto. 1998. Valuable shellfish species in the by-catch of shrimp fishery in southern Brazil: spatial and temporal patterns. J. Shellfish Res., 17(1): 303309.

Perry, R. I.; Walters, C. J. \& J. A. Boutillier. 1999. A framework for providing scientific advice for the management of new and developing invertebrate fisheries. Rev. Fish Biol. Fisheries, 9:125-150.

Pezzuto, P. R. 2001. Avaliação de estoque e dinâmica populacional da vieira Euvola ziczac (Linnaeus, 1758) (Bivalvia: Pectinidae) no sul do Brasil. Tese de Doutorado, Departamento de Zoologia, Universidade Federal do Paraná.

Pezzuto, P. R. \& C. A. Borzone. 1997. The scallop Pecten ziczac (Linnaeus, 1758) fishery in Brazil. J. Shellfish Res., 16 (2): 527-532.

Rodrigues, E. S. 1997. Biologia e pesca do lagostim Metanephrops rubellus (Moreira, 1903) desembarcado no litoral do estado de São Paulo, Brasil. Tese de Doutorado, Instituto de Biociências, Universidade Estatual Paulista "Júlio de Mesquita Filho". Santos, E. P. dos; G. S. Neiva \& Y. Schaeffer. 1969. Dinâmica da população do camarão sete-barbas Xiphopenaeus kroyeri (Heller) da Baía de Santos. Pesca \& Pesquisa, 2(2): 41-55.

SAPERJ. 2001. A lei e o sapo (Editorial). Pesca \& Mar. Informativo do Sindicato dos Armadores de Pesca do Estado do Rio de Janeiro. Ano XII, no 71, fevereiro de 2001.

Severino Rodrigues, E.; J. B. Pita; R. Graça Lopes; J. A. P. Coelho \& A. Puzzi. 1993. Aspectos biológicos e pesqueiros do camarão-sete-barbas (Xiphopenaeus kroyeri) capturado pela pesca artesanal no litoral do estado de São Paulo. B. Inst. Pesca, 19: 67-81.

SUDEPE/PDP, 1983. Relatório da Reunião Anual do Grupo Permanente de Estudos 
sobre Camarões da Região Sudeste-sul. Setembro de 1983, Santos/SP, 30 p.

Tomás, A.R.G. A pesca de emalhe no Estado de São Paulo. Boletim do Instituto de Pesca (submetido).

UNIVALI / MA. 2001. Relatório Final do Convênio MA/SARC/03/2000: Ações Prioritárias ao Desenvolvimento da Pesca e Aqüicultura do Sul do Brasil. Itajaí/SC; CTTMar/ UNIVALI.

Valentini, H.; F. D'Incao L. R. Rodrigues, J. E. Rebelo Neto \& L. Domit. 1991a. Análise da pesca do camarão-sete-barbas (Xiphopenaeus kroyeri) nas regiões sudeste e sul do Brasil. Atlântica, Rio Grande, 13(1): 171-177.

Valentini, H.; P. M. G. Castro; G. J. M. Servo \& L. A. B. Castro. 1991b. Evolução da pesca das principais espécies demersais da costa sudeste do Brasil, pela frota de arrasteiros de parelha baseada em São Paulo, de 1968 a 1987. Atlântica, Rio Grande, 13(1): 8795.

Valentini, H.; F. D'Incao; L. F. Rodrigues; J. E. Rebelo Neto \& E. Rahn. 1991c. Análise da pesca do camarão-rosa (Penaeus brasiliensis e Penaeus paulensis) nas re- giões sudeste e sul do Brasil. Atlântica, Rio Grande, 13(1): 143-158.

Vianna, M. 1998. Análise de populações de peixes teleósteos acompanhantes da pesca de arrasto do camarão-rosa (Penaeus brasiliensis e P. paulensis), em Ubatuba, SP: Captura, crescimento e mortalidade. Tese de Doutorado, Universidade Federal de São Carlos PPGERn-UFSCar, S. Carlos: 114

Vianna, M. , A.. R. G. Tomas \& J. R. Verani, J. R. 2000. Aspects of the biology of the atlantic midshipman, Porichthys porosissimus (Teleostei, Batrachoididae): On important by-catch species of shrimp trawling off southern Brazil. Rev. bras. Oceanogr., 48(2): 133-142.

Vieira, B. B. 1947. Observações sobre a maturação de Xiphopenaeus kroyerino litoral de São Paulo. Bol. Mus. Nac., 74: 122.

Vooren, C. M.; M. Haimovici; P. C. Vieira; \& V. S. Duarte. 1988. Pesca experimental na margem externa da plataforma e no talude continental do Rio Grande no inverno de 1986. Anais do V Congresso Brasileiro de Engenharia de Pesca, Fortaleza - CE, 435447. 
NOTAS TÉC. FACIMAR, 5: 1-34, 2001.

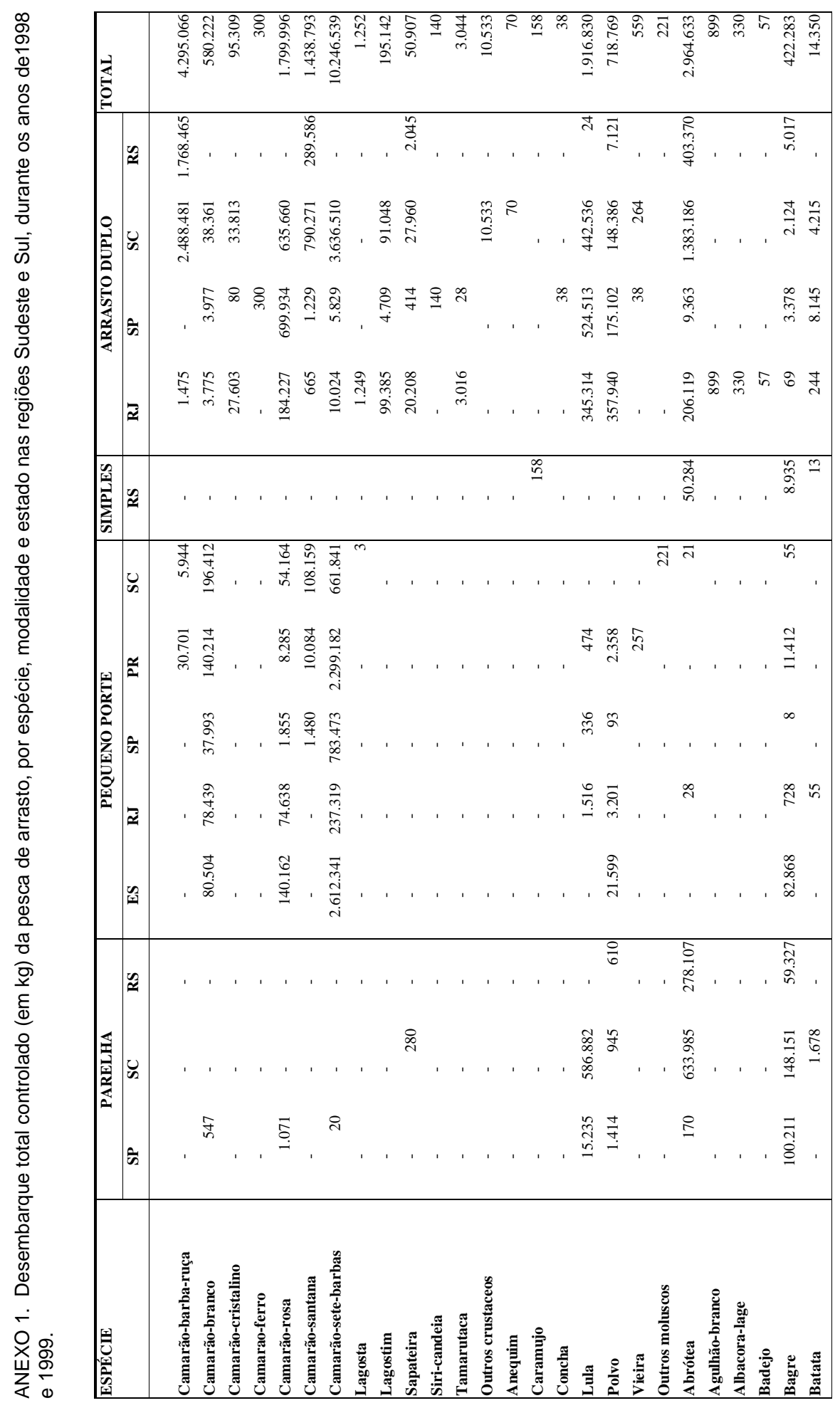


PEREZ et al:: Ordenamento da Pesca de Arrasto no Sudeste-Sul do Brasil.

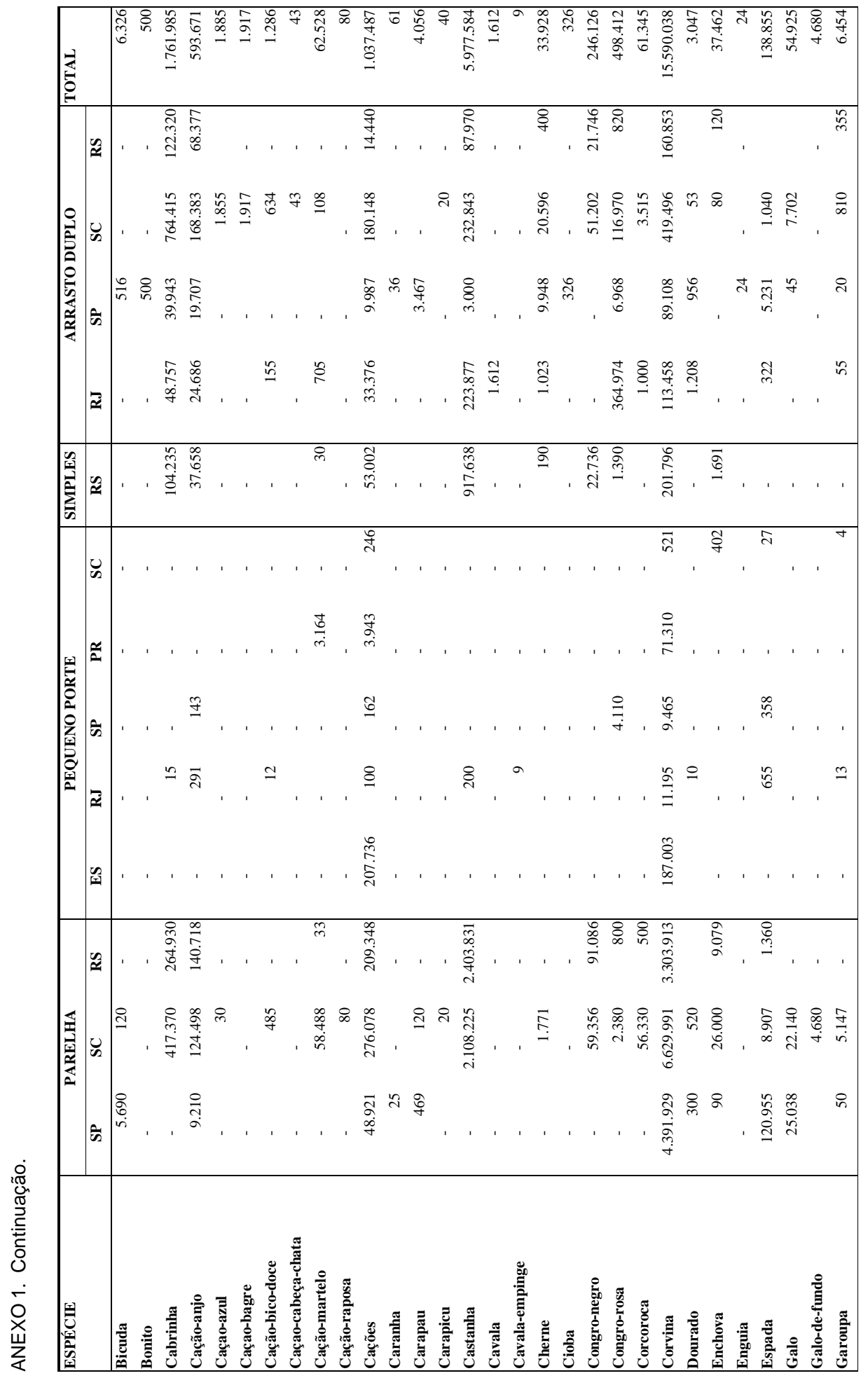




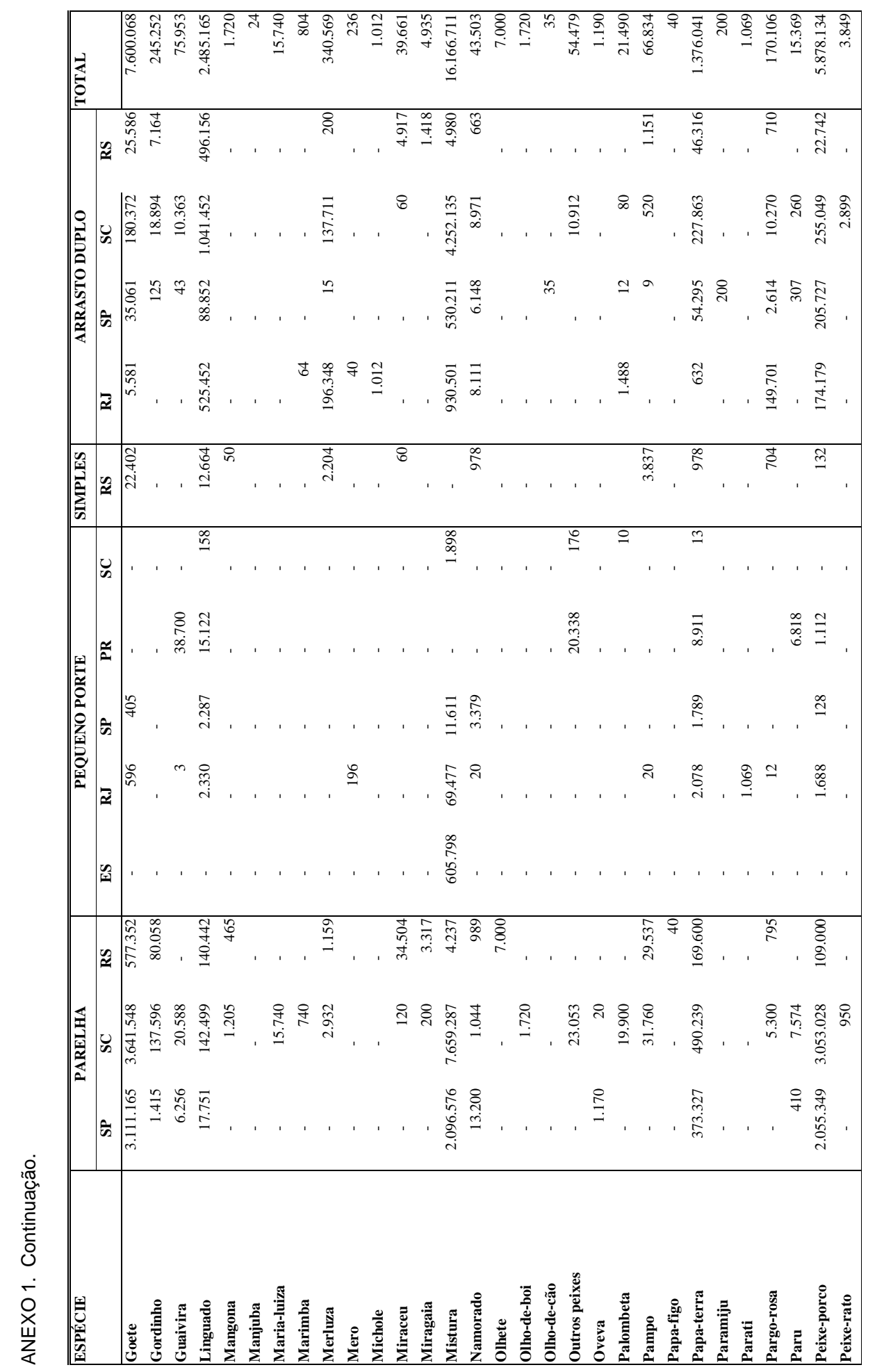




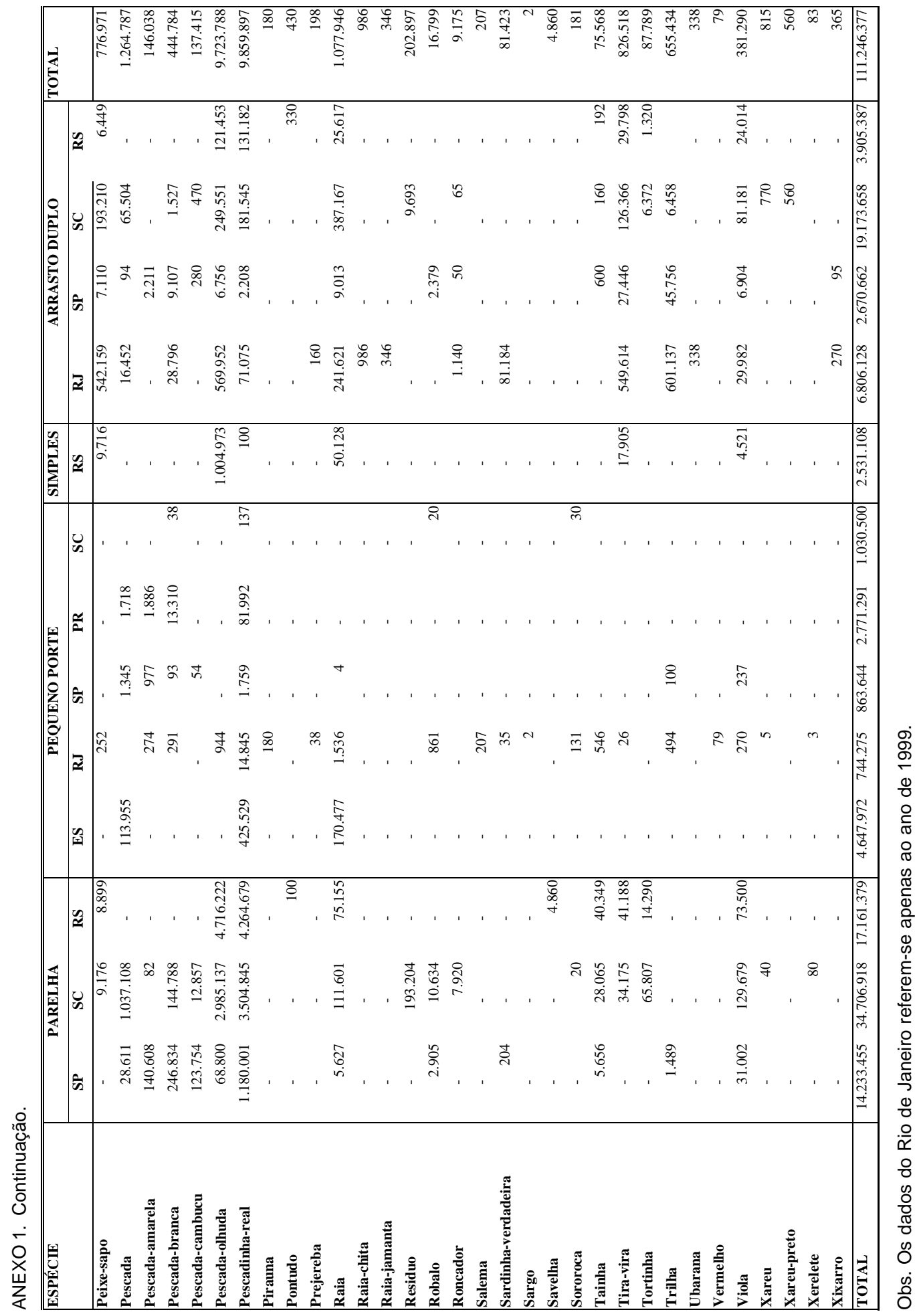


ANEXO 2. Desembarque total controlado (em $\mathrm{kg}$ ) da pesca de emalhe, por espécie e estado, nas regiões Sudeste e Sul, durante os anos de 1998 e 1999.

\begin{tabular}{|c|c|c|c|c|}
\hline ESPÉCIE & SP & SC & RS & TOTAL \\
\hline Abrótea & - & 226.810 & 115.453 & 342.263 \\
\hline Agulha & 3 & - & - & 3 \\
\hline Agulhão & 629 & 68 & - & 697 \\
\hline Agulhão-branco & 300 & - & - & 300 \\
\hline Agulhão-negro & 577 & - & - & 577 \\
\hline Agulhão-vela & 1.159 & - & - & 1.159 \\
\hline Albacora lage & - & - & 40 & 40 \\
\hline Albacora-bandolim & 15 & - & - & 15 \\
\hline Anequim & 1.126 & 5.930 & - & 7.056 \\
\hline Atum & 113 & - & - & 113 \\
\hline Bagre & 7.799 & 35.290 & 147.666 & 190.755 \\
\hline Batata & - & - & 891 & 891 \\
\hline Bicuda & 685 & - & - & 685 \\
\hline Bonito & 953 & - & 3.910 & 4.863 \\
\hline Bonito-listrado & - & 235 & - & 235 \\
\hline Cabrinha & - & 25.867 & 125.095 & 150.962 \\
\hline Cacao moro & - & - & 135 & 135 \\
\hline Cação-anjo & 58.848 & 854.670 & 220.438 & 1.133 .956 \\
\hline Cação-azul & - & 3.686 & - & 3.686 \\
\hline Cação-bico-doce & - & 14.702 & - & 14.702 \\
\hline Cação-cabeça-chata & - & 8.408 & - & 8.408 \\
\hline Cação-gato & - & & 1.340 & 1.340 \\
\hline Cação-martelo & 19.462 & 127.410 & 9.321 & 156.193 \\
\hline Cação-raposa & & & 5.522 & 5.522 \\
\hline Cações & 205.793 & 2.831 .023 & 613.165 & 3.649 .981 \\
\hline Carapau & 10 & & & 10 \\
\hline Castanha & 2.000 & 1.580 & 1.453 .771 & 1.457 .351 \\
\hline Cherne & - & - & 2.161 & 2.161 \\
\hline Cioba & 40 & - & - & 40 \\
\hline Congro-negro & - & - & 13.034 & 13.034 \\
\hline Congro-rosa & - & - & 5.443 & 5.443 \\
\hline Corvina & 438.377 & 4.322 .320 & 1.652 .706 & 6.413 .403 \\
\hline Dourado & 4.578 & 3.680 & 20 & 8.278 \\
\hline Emplastro & - & 1.320 & - & 1.320 \\
\hline Enchova & 545 & 210.455 & 912.379 & 1.123 .379 \\
\hline Espada & 13.145 & 71 & 113 & 13.329 \\
\hline Espadarte & 1.500 & - & - & 1.500 \\
\hline Galha & 294 & - & - & 294 \\
\hline Galha de cação & - & 1.070 & - & 1.070 \\
\hline Galo & 1.220 & - & - & 1.220 \\
\hline Garoupa & 15 & - & 3.711 & 3.726 \\
\hline Goete & 26.546 & - & 4.009 & 30.555 \\
\hline Gordinho & 355 & 4.827 & 5.150 & 10.332 \\
\hline
\end{tabular}


PEREZ et al.: Ordenamento da Pesca de Arrasto no Sudeste-Sul do Brasil.

ANEXO 2. Continuação.

\begin{tabular}{|c|c|c|c|c|}
\hline ESPÉCIE & SP & $\overline{\mathrm{SC}}$ & PSS & TOTAL \\
\hline \begin{tabular}{|l|} 
Guaivira \\
\end{tabular} & 44.085 & - & - & 44.085 \\
\hline Linguado & 1.899 & 6.110 & 30.340 & 38.349 \\
\hline Mangona & - & 45.503 & 2.135 & 47.638 \\
\hline Maria-luíza & 8 & - & - & 8 \\
\hline Maria-mole & 119 & - & - & 119 \\
\hline Merluza & - & - & 47.517 & 47.517 \\
\hline Miraceu & - & - & 1.611 & 1.611 \\
\hline Miracéu & - & - & 2.717 & 2.717 \\
\hline Miragaia & - & - & 34.722 & 34.722 \\
\hline Mistura & 53.569 & 389.935 & - & 443.504 \\
\hline Namorado & - & - & 816 & 816 \\
\hline Olhete & - & - & 757 & 757 \\
\hline Oveva & 260 & - & - & 260 \\
\hline Pampo & - & 2.330 & 93.528 & 95.858 \\
\hline Papa-figo & - & - & 100 & 100 \\
\hline Papa-terra & 49.135 & 163.023 & 67.009 & 279.167 \\
\hline Pargo-rosa & 5 & 3.960 & 7.119 & 11.084 \\
\hline Paru & 212 & - & - & 212 \\
\hline Peixe-porco & 6.567 & 1.337 & 6.536 & 14.440 \\
\hline Peixe-prego & - & 2.840 & - & 2.840 \\
\hline Peixe-rei & - & - & 1.763 & 1.763 \\
\hline Peixe-sapo & - & 1.278 & 5.629 & 6.907 \\
\hline Pescada & 869 & 14.700 & - & 15.569 \\
\hline Pescada-amarela & 4.709 & 3.780 & - & 8.489 \\
\hline Pescada-banana & 200 & - & - & 200 \\
\hline Pescada-branca & 3.591 & 20 & - & 3.611 \\
\hline Pescada-cambucu & 10.768 & - & - & 10.768 \\
\hline Pescada-olhuda & & 3.854 & 2.304 .041 & 2.307 .895 \\
\hline Pescadinha-real & 186.786 & 1.000 & 65.358 & 253.144 \\
\hline Polvo & - & - & 80 & 80 \\
\hline Pontudo & - & - & 3.277 & 3.277 \\
\hline Prejereba & 670 & - & - & 670 \\
\hline Raia & 1.842 & 206.192 & 41.575 & 249.609 \\
\hline Robalo & 190 & - & - & 190 \\
\hline Roncador & 3 & - & - & 3 \\
\hline Savelha & - & - & 28.480 & 28.480 \\
\hline Serrinha & - & - & 1.102 & 1.102 \\
\hline Sororoca & 3.020 & - & - & 3.020 \\
\hline Tainha & - & 35.458 & 329.333 & 364.791 \\
\hline Tira-vira & - & - & 16.587 & 16.587 \\
\hline Viola & 1.535 & 31.958 & 84.965 & 118.458 \\
\hline Xaréu & 300 & - & - & 300 \\
\hline Xixarro & - & - & 68.940 & 68.940 \\
\hline TOTAL & 1.156 .429 & 9.592 .700 & 8.541 .510 & 19.290 .639 \\
\hline
\end{tabular}

Obs.: Os dados do Rio Grande do Sul referem-se aos anos de 1999 e 2000. 
ANEXO 3. Síntese do estado de explotação dos estoques demersais do Sudeste-Sul do Brasil *

\begin{tabular}{|c|c|c|}
\hline GRUPO & ESPÉCIE & CONSIDERAÇÕES/RECOMENDAÇÕES \\
\hline I & $\begin{array}{l}\text { Corvina - Micropogonias } \\
\text { furnieri }\end{array}$ & $\begin{array}{l}\text { Estoque Sul - Capturas estáveis, com queda } \\
\text { acentuada na CPUE; indícios de sobreexplotação. } \\
\text { Estoque Sudeste - As capturas vêm ganhando maior } \\
\text { importância, inclusive por petrechos como cerco, } \\
\text { emalhe e espinhel de fundo. }\end{array}$ \\
\hline 1 & $\begin{array}{l}\text { Pescada-olhuda ou Maria } \\
\text { Mole-Cynoscion guatucupa }\end{array}$ & $\begin{array}{l}\text { Sem evidências conclusivas do estado do recurso no } \\
\text { Brasil, porém, com indícios de sobreexplotação no } \\
\text { Uruguai, com o qual o estoque é compartilhado. }\end{array}$ \\
\hline 1 & Castanha - Umbrina canosai & $\begin{array}{l}\text { Estoque sobreexplotado e compartilhado com o } \\
\text { Uruguai. }\end{array}$ \\
\hline 1 & $\begin{array}{l}\text { Pescadinha-real ou Pescada- } \\
\text { foguete - Macrodon ancylodon }\end{array}$ & $\begin{array}{l}\text { Estoque Sul - Plenamente explotado, com índices de } \\
\text { abundância (CPUE) oscilando em patamares estáveis, } \\
\text { porém em níveis inferiores aos da década de } 1970 \text {. } \\
\text { Estoque Sudeste - Demonstra indícios de } \\
\text { sobreexplotação, com queda nas capturas e nos } \\
\text { índices de abundância (CPUE), nos últimos } 20 \text { anos. }\end{array}$ \\
\hline 1 & Goête - Cynoscion jamaicensis & $\begin{array}{l}\text { Plenamente explotado, com índices de abundância } \\
\text { (CPUE) oscilando em patamares estáveis, porém em } \\
\text { níveis inferiores aos da década de } 1970 \text {. }\end{array}$ \\
\hline 1 & $\begin{array}{l}\text { Peixe-porco - Balistes } \\
\text { capriscus }\end{array}$ & $\begin{array}{l}\text { Grandes flutuações temporais, mostrando, porém, } \\
\text { aumento de importância nas capturas. }\end{array}$ \\
\hline 1 & $\begin{array}{l}\text { Abrótea - Urophycis } \\
\text { brasiliensis }\end{array}$ & $\begin{array}{l}\text { Plenamente explotada, apresentando sobrepesca de } \\
\text { crescimento. }\end{array}$ \\
\hline 1 & Bagres & $\begin{array}{l}\text { No sul, as informações disponíveis sobre Netuma spp. } \\
\text { revelam uma sobrepesca de recrutamento, desde a } \\
\text { década de } 1980 \text {. No sudeste, a pesca encontra-se em } \\
\text { acentuada expansão, podendo-se antecipar, pelas } \\
\text { características biológicas das espécies envolvidas } \\
\text { possibilidades de sobrepesca iminente. }\end{array}$ \\
\hline 1 & Linguados & $\begin{array}{l}\text { Plenamente explotados, apresentando indícios de } \\
\text { sobrepesca. }\end{array}$ \\
\hline 1 & Outras espécies & $\begin{array}{l}\text { Os demais teleósteos demersais de plataforma } \\
\text { constituem recursos de menor potencial pesqueiro, } \\
\text { sujeitos a uma igual pressão de pesca e suscetíveis a } \\
\text { um rápido processo de sobreexplotação }\end{array}$ \\
\hline & & ( \\
\hline II & $\begin{array}{l}\text { Cação bico-doce - } \\
\text { Galeorhinus galeus }\end{array}$ & Estoque já colapsado. \\
\hline II & Viola - Rhynobatos horkelii & Estoque já colapsado. \\
\hline II & $\begin{array}{l}\text { Caçonete (Cola-fina) - } \\
\text { Mustelus shmitti e Cação-anjo } \\
\text { - Squatina spp. }\end{array}$ & $\begin{array}{l}\text { Apresentam sobrepesca de recrutamento desde a } \\
\text { década de 1990, com perspectivas de diminuição da } \\
\text { produção sob o atual nível de esforço. }\end{array}$ \\
\hline
\end{tabular}


ANEXO 3. Continuação.

\begin{tabular}{c|c|c}
\hline \hline GRUPO & \multicolumn{1}{|c|}{ ESPÉCIE } & \multicolumn{1}{c}{ CONSIDERAÇÕES/RECOMENDAÇÕES } \\
\hline II & Emplastro e Raias & $\begin{array}{l}\text { Sujeitas, atualmente, a pescarias dirigidas e em } \\
\text { expansão, com a possibilidade do aumento da } \\
\text { produção nos próximos anos, especialmente para } \\
\text { algumas espécies de "emplastro". }\end{array}$
\end{tabular}

III Cherne-verdadeiro Epinephelus spp.

III Cherne-poveiro - Polyprion americanus

III Batata - Lopholatylus villarii

III Abrótea de profundidade Urophycis cirrata

III Peixe-sapo - Lophius gastrophysus, Congro-rosa Genypterus brasiliensis e raias da família Rajidae

IV Lula - Loligo plei

IV Lula - Loligo sanpaulensis

IV Lula - Illex argentinus

IV Camarão-rosa -

Farfantepenaeus paulensis e $F$. brasiliensis

IV Camarão-barba-ruça Artemesia longinaris e Camarão-santana - Pleoticus muelleri

\section{Camarão-cristalino -}

Plesionika longirostris
Na Região Sudeste é alvo de diversas frotas, mostrando evidências de sobreexplotação.

Na região sul não é objeto de pescaria dirigida.

Submetido a esforço de pesca muito intenso; pelas características de seu ciclo de vida, constitui-se em estoque susceptível a rápido colapso.

Na região sudeste encontra-se plenamente explotado, com CPUE declinante. Na região sul, não há mais pesca dirigida à espécie, desde o final da década de 1990.

Não há dados para avaliação do estado de explotação.

São componentes de uma mesma comunidade, sobre a qual o esforço de pesca vem aumentando de forma acentuada, face a seu elevado valor comercial. O impacto desta explotação deverá ser rapidamente avaliado.

Estoque anual de elevada variabilidade, havendo indícios de que o esforço dirigido atualmente pode remover parcela significativa do estoque.

Estoque subexplotado

Estoque subexplotado

Estoque colapsado

Plenamente explotado

Estoque subexplotado 
NOTAS TÉC. FACIMAR, 5: 1-34, 2001.

ANEXO 3. Continuação.

\begin{tabular}{c|ll}
\hline \hline GRUPO & \multicolumn{1}{c}{ ESPÉCIE } & \multicolumn{1}{c}{ CONSIDERAÇÕES/RECOMENDAÇÕES } \\
\hline IV & Polvo - Octopus vulgaris & Espécie anual, plenamente explotada. \\
IV & $\begin{array}{l}\text { Vieira - Euvola ziczac } \\
\text { Estoque colapsado }\end{array}$ \\
IV $\quad \begin{array}{l}\text { Caranguejo-vermelho - } \\
\text { Chaceon sp. e Geryon sp. }\end{array}$ & $\begin{array}{l}\text { Permanece recomendação do SCORE-Sul/REVIZEE } \\
\text { de não aumentar o esforço. }\end{array}$ \\
IV $\quad \begin{array}{l}\text { Lagostim - Metanephrops } \\
\text { rubellus }\end{array}$ & $\begin{array}{l}\text { Necessita de urgente avaliação do estoque. } \\
\text { Lagosta-sapateira - Scyllarides } \\
\text { deceptor }\end{array}$ & $\begin{array}{l}\text { Recurso com importância crescente nos } \\
\text { desembarques, demandando avaliação do estoque. }\end{array}$ \\
\hline \hline
\end{tabular}

Grupo I: peixes ósseos de plataforma

Grupo II: elasmobrânquios de plataforma

Grupo III: peixes de plataforma externa e talude

Grupo IV: invertebrados

* Elaborada pelo Grupo Técnico participante da Reunião sobre o Estado da Arte e Ordenamento da Pesca de Peixes Demersais nas Regiões Sudeste e Sul do Brasil (CEPSUL/IBAMA, ItajaíSC, $04-08 / 12 / 2000)$. 
PEREZ et al.: Ordenamento da Pesca de Arrasto no Sudeste-Sul do Brasil.

ANEXO 4. Conclusões do Grupo Técnico participante da Reunião sobre o Estado da Arte e Ordenamento da Pesca de Camarões nas Regiões Sudeste e Sul do Brasil (CEPSUL/IBAMA, Itajaí-SC, 06 - 11/11/2000).

- O estoque oceânico de camarão-rosa encontra-se em nível baixo de abundância.

- A pesca artesanal do camarão-rosa nas áreas de criadouro tem fundamental influência na abundância do estoque reprodutor marinho. Caso essa atividade não seja devidamente ordenada, não há perspectiva de recuperação do estoque oceânico.

- A frota de camaroneiros não mais se sustenta apenas da captura do camarão-rosa, mas sim do maior aproveitamento de espécies da fauna acompanhante de valor comercial, e/ou do direcionamento do seu esforço para espécies disponíveis ao arrasto, porém, não necessariamente componentes do bycatch do camarão-rosa.

- A explotação dessas espécies é desordenada e pode ser significativa tanto pelo elevado esforço, muitas vezes concentrado no tempo e no espaço sobre um determinado recurso, como pelo menor tamanho de malha empregado.

- Pode-se considerar que a frota de arrasteiros de tangones não mais se caracteriza pela atuação específica sobre um recurso, o camarão-rosa, mas sim como participante de uma pescaria multiespecífica, em conjunto com os outros arrasteiros do Sudeste-Sul. Essa situação tem sido favorecida pelo sistema atual de licenciamento e implica em uma reformulação das medidas de manejo, dentro de uma ótica de pesca de arrasto e não mais de espécies controladas.

- O período de desova do camarão-sete-barbas no Sudeste-Sul ocorre principalmente na primavera, não estando, portanto, protegido pelo defeso de recrutamento do camarão-rosa, ao qual está submetido. Além disso, estudos demonstraram que os melhores rendimentos do camarão setebarbas são obtidos justamente na época do defeso do camarão-rosa. 